\title{
Analysis of Formwork System Selection Criteria for Building Construction Projects: A Comparative Study
}

\author{
Taylan Terzioglu (D, Gul Polat *(D) and Harun Turkoglu (D) \\ Department of Civil Engineering, Istanbul Technical University, Istanbul 34469, Turkey; \\ terzioglu17@itu.edu.tr (T.T.); hturkoglu@itu.edu.tr (H.T.) \\ * Correspondence: polatgu@itu.edu.tr; Tel.: +90-212-285-3737
}

Citation: Terzioglu, T.; Polat, G.; Turkoglu, H. Analysis of Formwork System Selection Criteria for Building Construction Projects: A Comparative Study. Buildings 2021, 11, 618 . https://doi.org/10.3390/buildings 11120618

Academic Editor:

Jurgita Antucheviciene

Received: 1 November 2021

Accepted: 2 December 2021

Published: 6 December 2021

Publisher's Note: MDPI stays neutral with regard to jurisdictional claims in published maps and institutional affiliations.

Copyright: (C) 2021 by the authors. Licensee MDPI, Basel, Switzerland. This article is an open access article distributed under the terms and conditions of the Creative Commons Attribution (CC BY) license (https:// creativecommons.org/licenses/by/ $4.0 /)$.

\begin{abstract}
The formwork system (FWS) in reinforced concrete (RC) construction is a critical component. The appropriate FWS is selected based on a number of conflicting and compromising criteria, and the selection of the FWS is carried out by construction professionals with different technical and/or administrative backgrounds. The perspectives and perceptions of construction professionals and companies involved in the FWS selection process may vary depending on their motives. In addition, some building structural parameters may have a significant impact on the FWS selection criteria. Most of the former studies investigated the FWS selection criteria from only the perspective of contractors and neglected the potential differences in the perspectives and perceptions of different construction professionals (i.e., owners (CO), project managers (PM), construction managers (CM), site engineers (SE), planning engineers (PL), procurement engineers (PR), technical office engineers (TO), and formwork design and/or formwork sales engineers (FD/FSL)) and companies specialized in different fields (i.e., project management service (PMS), engineering and design (ENG/DSG), formwork and scaffolding (FW/SCF), and general and/or sub-contractor (GC/SC)) regarding this issue. Moreover, the impact of building structural parameters on the FWS selection criteria has not been investigated. This study aims to fill this knowledge gap through analysing the FWS selection criteria for building construction projects while comparing the perspectives and perceptions of different groups of construction professionals and companies and investigating how FWS selection criteria are affected by the building structural parameters. Based on a comprehensive literature review, 35 FWS selection criteria were identified and a questionnaire was developed. The questionnaire data obtained from 222 Turkish construction professionals were statistically analysed using mean score analysis, the Kruskal-Wallis test, and the Mann-Whitney U test. According to the study's findings, the FD/FSL group presented significant statistical differences regarding the FWS selection criteria as compared to the CO, PM/CM/SE, and PL/PR/TO groups. Moreover, the total area of building construction and total building height significantly affected the FWS selection criteria. This study serves to underscore the perspectives of various groups of construction professionals and the critical connection between the structural parameters and FWS selection criteria. The findings of this study may guide construction professionals to select the appropriate FWS for their building construction projects.
\end{abstract}

Keywords: buildings; construction projects; formwork systems; selection criteria; building structural parameters; questionnaire

\section{Introduction}

RC construction involves repetitive activities, with formwork, rebar, and concrete being the main components of these activities in building construction projects [1]. Formwork accounts for a major part of the RC structure's cost [2]. For instance, the selected FWS may contribute to up to two-thirds of the entire cost of the RC structural frame [3] and 10\% of the total construction cost [4]. In Turkey, the labour cost of formwork accounts for 10 to $15 \%$ of the total cost of a building construction project [5]. Advancements in formwork 
engineering may significantly reduce the cost and material waste while improving the potential of a project's success [6]. In addition, the selected FWS may have a significant impact on the project's overall duration [7] as well as the safety and quality of a building construction project [8]. Therefore, as RC construction developed, construction professionals in the field of formwork engineering were required to provide solutions by developing new FWSs [9]. The FWS may be selected based on a variety of criteria, some of which are interdependent [10]. Furthermore, the relative importance level of the FWS selection criteria, and thus the selection of the appropriate FWS, may depend on the perception of different project stakeholders, such as contractors [11], or on the perception of different construction professionals, such as formwork planning engineers [12].

Most of the previous studies in the relevant literature identified, ranked, and analysed FWS selection criteria based on a certain group of construction professionals or stakeholders $[7,11,12]$. In addition, few studies have compared the perspectives and perceptions regarding the relative importance level of FWS selection criteria among a particular group of respondents (e.g., contractors) [13]. However, no prior study has investigated whether there are any significant statistical differences/disagreements in the relative importance of FWS selection criteria among different groups of construction professionals and/or companies. Moreover, some building structural parameters (e.g., total building area, total building height) of the building construction project may significantly affect the FWS design and selection $[14,15]$. Hence, the effects, if any, of the building structural parameters on the FWS selection criteria may reveal some valuable insights for construction professionals in their decision-making process.

As the selection of the FWS is considered as a difficult task and requires the early involvement of all the stakeholders in the early phases of a project (e.g., formwork fabricator (FWF)) [16], analysing the perspectives and perceptions of different groups of construction professionals and companies regarding the FWS selection criteria may improve the project performance factors. The main objectives of this study include (1) comparing the perspectives and perceptions of the different groups of construction professionals and companies on the FWS selection criteria, and (2) identifying the effects of the building structural parameters on the FWS selection criteria. The results of this study can also be used by decision-makers and construction professionals involved in the selection process of FWSs.

\section{Literature Review}

Throughout the twentieth century, formwork engineering developed in lockstep with the expansion of concrete construction [17]. The developments and technological advancements in formwork engineering led to the widespread use of industrial FWSs across the world [18]. Since there are many FWSs available, the selection of the appropriate FWS depends on various compromising and conflicting criteria $[7,19]$. Therefore, a number of quantitative and qualitative criteria have been identified in previous studies that may affect the selection of FWSs in building construction projects. The majority of these studies have identified and/or ranked the FWS selection criteria $[13,20]$, while others have employed multi-criteria-decision-making (MCDM) methods to solve the FWS selection problem [2,21]. The following is a brief chronological summary of these studies.

Initially, Hanna [22] identified 38 factors for the FWS selection problem in building construction projects in the United States and grouped them into four categories based on expert opinion: building design, job specification, local conditions, and supporting organisation. Then, Hanna and Sanvido [23] developed an interactive expert system for the vertical FWS selection problem, specifically for contractors, based on Hanna's [22] factors and FWS alternatives. Analogously, the study by Hanna et al. [24] provided a rule-based expert system for decision-makers and formwork design engineers to select the most appropriate FWS (e.g., horizontal and vertical FWS) in building construction projects. Building structural parameters, such as the total building height, total area of building construction, and typical building floor area, were introduced as factors affecting 
the FWS selection [20,22-24]. Selecting the appropriate FWS can be a complex process [7]. Therefore, neural network (NN) models [2,25-27] and decision tree (DT) models $[7,28]$ have been developed to solve the FWS selection problem based on the factors identified by Hanna's [22] study. In these studies, additional building structural parameters affecting the FWS selection, such as floor area and number of floors, were incorporated into the relevant literature. Hanna [20] introduced labour productivity as an additional factor to the relevant literature in an extended version of the previously stated rules and guidelines for selecting FWSs. Proverbs et al. [13] analysed and compared the relative importance levels of nine factors affecting FWS selection among contractors and planning engineers from the UK, France, and Germany and determined the degree of agreement between them. Jarkas [29] measured the labour productivity of the selected FWS based on building structural parameters. Elbeltagi et al. [21] and Elbeltagi et al. [30] presented fuzzy logic models to select horizontal and vertical FWSs, respectively, based on the five most important FWS selection factors for Egyptian formwork engineering experts.

From 1989 to 2012, the majority of the studies regarding the FWS selection problem focused on the FWS selection criteria under the four main groups presented by Hanna [24]. Novel challenges in architectural and structural design, such as those in free-form concrete buildings with irregular and curved geometries, required new developments in formwork technology [31]. In addition, the popularity of industrial FWSs in building construction projects throughout the world, along with the introduction of new FWSs [32], prompted the inclusion of additional FWS selection criteria in the years that followed. For example, Krawczyska-Piechna [33], Krawczyska-Piechna [34], and Krawczyska-Piechna [35] extended the relevant literature by proposing FWS flexibility, durability, compatibility, safety, and weight as additional criteria focusing on contractor preferences in Poland. In the context of the FWS safety criterion, since on-site formwork activities (e.g., erecting, stripping, or moving of the FWS) are associated with a high level of accidents [36], research on the safety aspects of these activities [37] and the safety of the FWS has gained more importance in the field of construction management. Furthermore, the compatibility and durability of the FWS may be critical factors when selecting an appropriate FWS [38]. Jiang et al. [39] introduced floor-to-floor height as a building structural parameter to the literature and used it for developing a DT model for the FWS selection problem. Martinez et al. [40] utilized the Choosing by Advantages (CBA) method with 14 selection factors for the FWS selection problem in Ecuador based on the knowledge of a team of project managers, planning engineers, and procurement engineers. FWS complexity and FWS size were added into the literature as new FWS selection factors. Radziejowska and Sobotka's [41] study incorporated the expertise of site managers and contractors in Poland, and eight FWS selection criteria for vertical FWS were identified. In their study, some criteria were related to the characteristics of the FWS, such as FWS durability, weight, and size. Hence, the majority of these recently identified criteria may be grouped under a new category, namely FWS characteristics, because they describe the different properties of the FWS. Loganathan and Viswanathan [42] evaluated the effects of FWS alternatives on the cost, time, and quality performance of high-rise building construction projects in India.

As material waste in RC construction is common [43,44], the sustainability of the FWS has become an important factor in recent years [45]. In addition, building information modelling (BIM) applications used in formwork engineering can greatly improve the sustainability of a project [46]. Therefore, some recent studies introduced the degree of formwork material recycling (i.e., FWS sustainability) and the degree of BIM applications for FWSs (i.e., FWF BIM support) to the relevant literature [4]. For instance, Singh et al. [47] used a BIM approach to automate the design and selection process of the FWS by utilizing some building structural parameters (e.g., floor height) in their model. Basu and Jha [12] used factor analysis to group the FWS selection criteria identified by Hanna et al. [24] and analytical hierarchy process (AHP) to determine the most significant FWS selection criterion groupings for formwork planning engineers in India. Similarly, Rajeshkumar and Sreevidya [48] and Rajeshkumar et al. [17] identified and grouped 40 FWS selection criteria 
into five categories by utilizing factor analysis and investigated the degree of agreement regarding the FWS selection criteria among clients, contractors, and consultants in the Indian building construction sector. Transportation cost was also introduced as a new criterion for selecting FWSs. Pawar et al. [49] and Teja et al. [50] determined the relative importance index (RII) of previously identified FWS selection criteria for different FWS alternatives commonly used in India. Lohana's [51] study revealed that the productivity criterion for selecting FWSs in building construction projects can be quantified as a function of cost, cycle time, and the degree of repetition of FWS. Ray et al. [52] performed a breakeven analysis on two commonly used industrial FWSs in India, considering the total cost of the FWS by incorporating the degree of repetition, initial cost, and maintenance cost of the FWS in their calculation. Huszar and Lubloy [53] compared the cost of the FWS to the total cost of a building construction project while citing the initial cost of the FWS, speed of construction, FWS flexibility, and FWS safety as attributes of the selected FWS. Rajeshkumar et al. [54] compared the cost, time, productivity, and quality performance factors of three commonly used FWSs in building construction projects. Terzioglu et al. [10] carried out a critical review of the literature on FWS selection criteria for building construction projects, identifying 35 FWS selection criteria in total and demonstrating that several structural design criteria are interdependent with FWS characteristics-related criteria.

In the literature, several researchers focused on identifying the FWS selection criteria and/or determining their relative importance levels through interviews with experts and questionnaire surveys conducted in different countries, such as Korea, UK, France, Germany, India, Egypt, and Ecuador [7,13,17,21,30,40]. However, there has been no study conducted in order to identify and/or rank the FWS selection criteria in the Turkish building construction sector. The Turkish construction sector has an annual GDP share of 5 to $6.5 \%$ and an employment share of 5 to $7 \%$ [55]. In addition, Turkish contractors have completed 10,725 projects in 128 countries, with a total value of 424.5 billion US dollars from 1971 to 2021 [56]. In 2020, Turkish contracting companies have undertaken 348 projects in 57 countries with a total value of 15.1 billion US dollars [56]. Moreover, according to Engineering News-Record (ENR), 44 Turkish construction companies were listed among the top 250 international contractors in 2020, placing Turkish contractors in the second place after China [57]. Therefore, there is a need to identify and/or rank the FWS selection criteria in the Turkish building construction sector. This issue raises a research question:

- Q1: Which of the identified FWS selection criteria are being considered by the companies and construction professionals in their decision-making process, and what are the relative importance levels of these FWS selection criteria in the Turkish building construction sector?

The supply chain activities associated with formwork and the selection of the FWS may be performed by different project stakeholder groups (e.g., engineer, contractor, FWF) at different phases of a building construction project [16]. In addition, stakeholders, such as contractors, may be more inclined to minimize the cost and maximize the quality and safety of the FWS [3], while FWFs may mostly be concerned with the technical and design aspects of the FWS [58]. Therefore, FWS selection may vary depending on the perspectives and perceptions of the different project stakeholder groups. However, the majority of the former studies concentrated solely on the contractors or their employees as project stakeholder groups [11,13,33-35]. Moreover, none of these studies have investigated if any disagreements exist among different groups of construction professionals and/or companies regarding the importance level of the FWS selection criteria. Potential differences in the perspectives and perceptions of different project stakeholder groups (i.e., construction professionals and companies) on the importance levels of the FWS selection criteria raise two important questions. 
- Q2: What are the differences, if any, in the relative importance levels of FWS selection criteria according to the "professional title" of the construction professionals?

- Q3: What are the differences, if any, in the relative importance levels of FWS selection criteria according to the "field of specialization" of the companies?

These are legitimate research questions to address because identifying the agreements or disagreements regarding FWS selection criteria among all the stakeholder groups can improve the selection process and thereby the overall project performance by taking their perspectives and perceptions into account at the early phases of the project.

It is generally claimed that building structural parameters (i.e., typical building floor area, total area of building construction, typical building floor-to-floor height, total building height) play a significant role in the FWS selection process $[7,26,30,50]$. For example, conventional FWSs are suitable for buildings with a total building height up to $36.5 \mathrm{~m}$ (i.e., low-rise buildings) [2,24] and a floor-to-floor height less than $5 \mathrm{~m}$ [30]. As another example, modern and modular FWSs (i.e., industrial FWSs) are typically suitable for a total building height greater than $36.5 \mathrm{~m}$ (i.e., mid-rise and/or high-rise buildings) $[4,20,24,25,49]$ and a floor-to-floor height greater than 4-5 m [14,20]. Similarly, conventional FWSs are usually selected if the total area of construction is less than $20,000 \mathrm{~m}^{2}$, and industrial FWSs are selected if the total area of construction is more than $20,000 \mathrm{~m}^{2}[20,26]$. As a result, changes in the values of the building structural parameters have a significant impact on the FWS selection process.

The selection of an appropriate FWS is based on a number of conflicting and compromising criteria. Therefore, changes in the values of the building structural parameters may affect the importance levels of the FWS selection criteria. However, no research has been conducted to investigate how the importance levels of FWS selection criteria differ depending on the changes in the values of the building structural parameters. This is a research gap. This potential relationship raises another research question:

- Q4: What are the differences, if any, in the relative importance levels of FWS selection criteria according to the changes in the values of the "building structural parameters" (e.g., building type, total building area, total building height, typical building floor area, typical building floor-to-floor height)?

Finally, the most critical FWS selection criteria should be identified. In this context, the final research question is:

- Q5: What are the critical FWS selection criteria in building construction projects?

The main objective of this study is to answer these research questions and to fill the important knowledge gap by comparing the perspectives and perceptions of different construction professionals and stakeholder groups in building construction projects in Turkey, and analysing the FWS selection criteria in relation to some building structural parameters and to determine how the importance levels of the FWS selection criteria differ according to the changes in the values of the building structural parameters.

\section{Research Methodology}

Initially, a thorough review of the relevant literature was conducted to identify the FWS selection criteria for building construction projects. Then, a questionnaire was developed as the main research instrument to answer the aforementioned five research questions. This section describes the research methodology for analysing the FWS selection criteria in building construction projects in Turkey. The research methodology of this study consists of five main stages, which are: (1) identification of FWS selection criteria, (2) design of the questionnaire, (3) data collection, (4) data analysis, and (5) discussion. The flowchart of the research methodology is shown in Figure 1. 


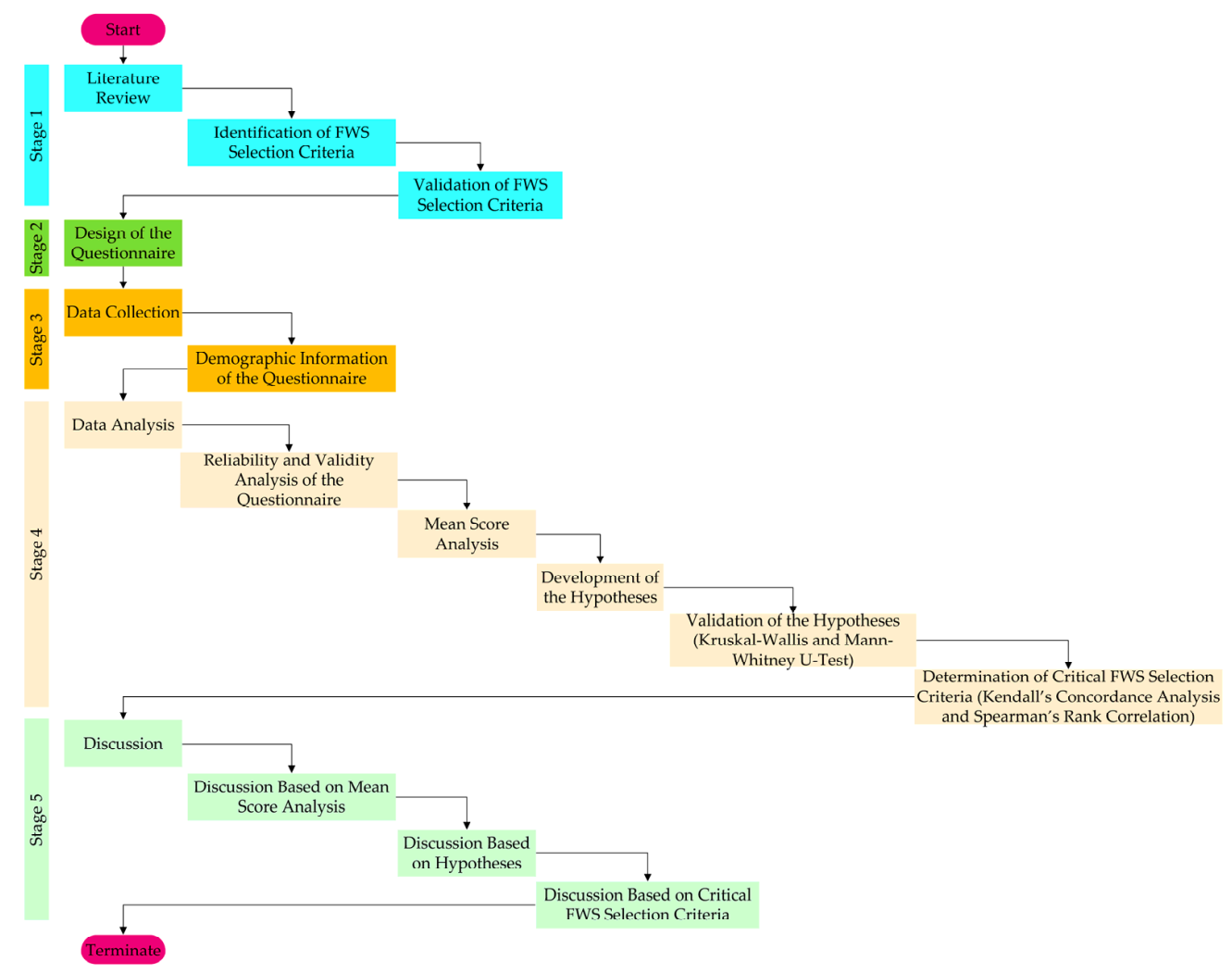

Figure 1. Research flowchart.

\subsection{Identification of FWS Selection Criteria}

Following a comprehensive review of the literature, a list of 35 FWS selection criteria for building construction projects was identified. Figure 2 illustrates the identified FWS selection criteria from the literature review along with their related ID numbers and the number of citations. The study by Terzioglu et al. [10] provides a detailed description of each of these FWS selection criteria, as well as a critical review of the relevant literature. In addition, Terzioglu et al. [10] validated the identified FWS selection criteria through face-toface interviews with several experts from the Turkish construction sector. As a result, the FWS selection criteria of this study are based on the findings of Terzioglu et al. [10], which include all previously identified FWS selection criteria in a single body of knowledge.

\subsection{Design of the Questionnaire}

Questionnaires are frequently used in construction management studies $[59,60]$ as an effective tool for researchers to collect quantitative data and utilize statistical methods to gain insights into personal perceptions and organisational policies and practices [61,62]. The questionnaire was developed using the FWS selection criteria identified through the literature review. The demographic information was presented at the beginning of the questionnaire to provide insight on the respondents' and company background (e.g., "professional title", "field of specialization") and ensure accurate responses.

The questionnaire's main body was divided into two sections. The first section was intended to obtain specific qualitative (e.g., building type) and quantitative (e.g., typical building floor area, typical building floor-to-height) information on the building construction project in which the respondents are presently working. In the second section, respondents were asked to rank the relative importance of each of the 35 FWS selection criteria in respect to the current building construction project on which they are participating. To evaluate the relative importance of each FWS selection criterion in the decision-making process, an ordinal six-point Likert scale was adopted ( 0 -not considered, 1 -not important, 2-slightly important, 3-moderately important, 4-very important, and 5-extremely 
important). Using a six-point Likert scale in questionnaires results in higher convergent validity when compared to four-point or five-point Likert scales [63,64]. In addition, there is a slight difference in the response rates between six-point and seven-point Likert scales [65]. Hence, this study adopted a six-point Likert scale, which was successfully used in the construction management studies, e.g., [66].

\begin{tabular}{|c|c|c|c|c|c|c|c|c|c|c|c|c|c|c|c|c|c|c|c|c|c|c|c|c|c|c|c|c|c|}
\hline ID Numbers & FWS Selection Criteria & 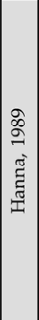 & 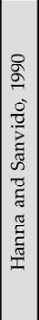 & 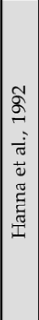 & 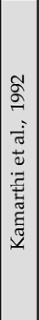 & 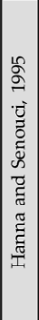 & 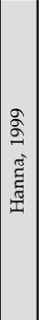 & 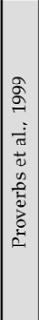 & 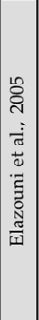 & 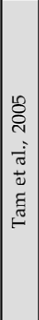 & 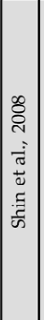 & 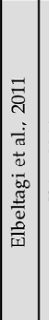 & $\begin{array}{l}= \\
\overline{\tilde{\sigma}} \\
\text { के } \\
\text { क }\end{array}$ & 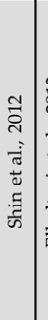 & 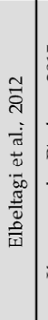 & 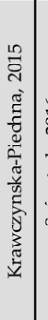 & 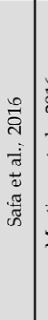 & 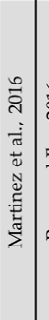 & 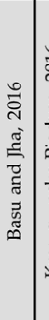 & 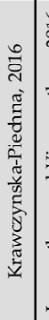 & 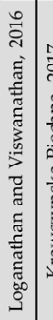 & 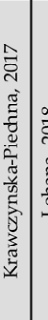 & 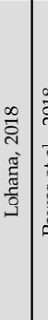 & 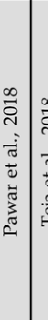 & 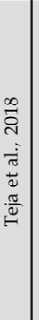 & 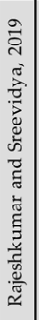 & 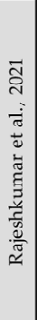 & 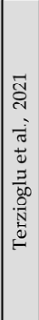 & 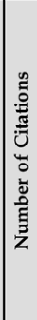 \\
\hline 1 & Type of structural slab & $\checkmark$ & & $\checkmark$ & & $\checkmark$ & $\checkmark$ & $\checkmark$ & $\checkmark$ & & $\checkmark$ & $\checkmark$ & $\checkmark$ & $\checkmark$ & & & & & $\checkmark$ & & $\checkmark$ & & & & $\checkmark$ & $\checkmark$ & $\checkmark$ & $\checkmark$ & 16 \\
\hline 2 & Type of structural lateral loads-supporting system & $\checkmark$ & $\checkmark$ & $\checkmark$ & $\checkmark$ & & $\checkmark$ & $\checkmark$ & $\checkmark$ & $\checkmark$ & & & & & $\checkmark$ & & & & $\checkmark$ & & $\checkmark$ & & & & $\checkmark$ & $\checkmark$ & $\checkmark$ & $\checkmark$ & 15 \\
\hline 3 & Total building height & $\checkmark$ & $\checkmark$ & $\checkmark$ & $\checkmark$ & & $\checkmark$ & $\checkmark$ & $\checkmark$ & $\checkmark$ & $\checkmark$ & & $\checkmark$ & $\checkmark$ & & & & & $\checkmark$ & & & & & & & $\checkmark$ & $\checkmark$ & $\checkmark$ & 15 \\
\hline 4 & Variation in column/wall dimcnsions and location & 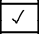 & 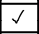 & $\checkmark$ & & & $\checkmark$ & & & & & & & & & & & & & & & & & & & & & $\checkmark$ & 5 \\
\hline 5 & Variation in openings/inserts dimensions and location & $\begin{array}{ll}\checkmark \\
\end{array}$ & 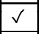 & $\begin{array}{ll}\checkmark \\
\end{array}$ & & & $\checkmark$ & & & & & & & & & & & & & & & & & & & & & $\checkmark$ & 5 \\
\hline 6 & Degree of repetition of the FWS & $\checkmark$ & $\checkmark$ & $\checkmark$ & & & & $\checkmark$ & & & & & $\checkmark$ & $\checkmark$ & & & $\checkmark$ & $\checkmark$ & $\sqrt{ }$ & & & & $\checkmark$ & $\checkmark$ & & $\checkmark$ & $\checkmark$ & $\checkmark$ & 14 \\
\hline 7 & Number of floors & & & & & & & & & & & & $\checkmark$ & $\checkmark$ & & & & & $\checkmark$ & & & & & & & $\checkmark$ & $\checkmark$ & $\checkmark$ & 6 \\
\hline 8 & Floor area & & & & & & & & & & $\sqrt{ }$ & & $\sqrt{ }$ & $\sqrt{ }$ & & & & & $\sqrt{ }$ & & & & & 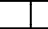 & & $\sqrt{ }$ & $\sqrt{ }$ & $\sqrt{ }$ & 7 \\
\hline 9 & Floor to floor height & $\checkmark$ & & $\checkmark$ & & $\checkmark$ & $\checkmark$ & $\checkmark$ & $\checkmark$ & & $\checkmark$ & & & & $\checkmark$ & & & & & & & & & & $\checkmark$ & $\checkmark$ & $\checkmark$ & $\checkmark$ & 12 \\
\hline 10 & Uniformity of building & $\checkmark$ & & $\checkmark$ & $\checkmark$ & $\checkmark$ & $\checkmark$ & $\checkmark$ & $\checkmark$ & $\checkmark$ & $\checkmark$ & & $\checkmark$ & $\checkmark$ & $\checkmark$ & & & & $\checkmark$ & & & & & varar & $\checkmark$ & & $\checkmark$ & $\checkmark$ & 16 \\
\hline 11 & Type of concrete finish & $\checkmark$ & 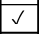 & $\checkmark$ & $\checkmark$ & & $\checkmark$ & $\sqrt{ }$ & $\sqrt{ }$ & $\checkmark$ & & & & & & $\checkmark$ & 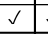 & $\checkmark$ & $\sqrt{ }$ & $\checkmark$ & $\sqrt{ }$ & $\checkmark$ & & $\sqrt{ }$ & $\checkmark$ & & $\checkmark$ & $\checkmark$ & 19 \\
\hline 12 & Speed of construction & $\checkmark$ & $\checkmark$ & $\checkmark$ & & $\checkmark$ & $\checkmark$ & $\checkmark$ & $\checkmark$ & & $\checkmark$ & $\checkmark$ & $\checkmark$ & $\checkmark$ & $\checkmark$ & $\checkmark$ & $\checkmark$ & $\checkmark$ & $\checkmark$ & $\checkmark$ & $\checkmark$ & $\checkmark$ & $\checkmark$ & $\checkmark$ & $\checkmark$ & $\checkmark$ & $\checkmark$ & $\checkmark$ & 25 \\
\hline 13 & Labor quality & $\begin{array}{ll}\checkmark \\
\end{array}$ & $\begin{array}{ll}\checkmark \\
\end{array}$ & $\checkmark$ & & $\checkmark$ & $\checkmark$ & $\checkmark$ & $\checkmark$ & & & $\checkmark$ & & & & & & & $\checkmark$ & & $\begin{array}{ll}\checkmark \\
\end{array}$ & & & $\checkmark$ & $\checkmark$ & & & $\checkmark$ & 13 \\
\hline 14 & Labor productivity & & & & & & $\checkmark$ & & & & & & & & & & $\checkmark$ & & & & $\checkmark$ & & & & $\checkmark$ & & $\checkmark$ & $\begin{array}{ll}\checkmark \\
\end{array}$ & 6 \\
\hline 15 & Weather conditions & $\begin{array}{ll}\checkmark \\
\end{array}$ & $\checkmark$ & $\checkmark$ & & & $\checkmark$ & & $\checkmark$ & & & & & & & & & & $\checkmark$ & & $\checkmark$ & & & & $\checkmark$ & $\checkmark$ & $\checkmark$ & $\checkmark$ & 11 \\
\hline 16 & Site access & 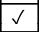 & 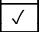 & $\checkmark$ & $\mathrm{J}$ & & $\checkmark$ & $\sqrt{\prime}$ & \begin{tabular}{|l} 
\\
\end{tabular} & $\sqrt{\prime}$ & & & & & & & & & $\checkmark$ & & $\sqrt{ }$ & & & & $\sqrt{ }$ & $\checkmark$ & $\begin{array}{ll} \\
\end{array}$ & $\begin{array}{ll} \\
\end{array}$ & 14 \\
\hline 17 & Size of site & $\checkmark$ & $\checkmark$ & $\checkmark$ & & $\checkmark$ & $\checkmark$ & & $\checkmark$ & & & & & & & & & & $\checkmark$ & & & & & & & & & $\checkmark$ & 8 \\
\hline 18 & Initial cost of the FWS & $\begin{array}{ll}\checkmark \\
\end{array}$ & & $\checkmark$ & & & $\checkmark$ & $\checkmark$ & $\checkmark$ & & & $\checkmark$ & & & $\checkmark$ & $\checkmark$ & $\checkmark$ & & $\checkmark$ & $\checkmark$ & $\checkmark$ & $\sqrt{ }$ & $\sqrt{ }$ & $\checkmark$ & $\checkmark$ & $\checkmark$ & $\checkmark$ & $\checkmark$ & 19 \\
\hline 19 & Transportation cost of the FWS & & & & & & & & & & & & & & & & & & & & & & & & & $\sqrt{ }$ & $\checkmark$ & $\checkmark$ & 3 \\
\hline 20 & Maintenance cost of the FWS & & & & & & & & & & & & & & & & & & & & $\bar{v}$ & & & & $\checkmark$ & $\checkmark$ & $\checkmark$ & 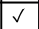 & 5 \\
\hline 21 & Labor cost of the FWS & 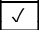 & 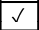 & 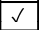 & & & $\checkmark$ & & $\sqrt{ }$ & & & $\sqrt{ }$ & & & & & $\checkmark$ & & $\sqrt{ }$ & & $\sqrt{ }$ & & $\sqrt{ }$ & & $\sqrt{ }$ & $\checkmark$ & $\sqrt{ }$ & 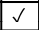 & 14 \\
\hline 22 & Potential reuse of the FWS in other projects & $\checkmark$ & & $\checkmark$ & & $\checkmark$ & $\checkmark$ & & $\checkmark$ & & & $\checkmark$ & & & & & $\checkmark$ & & $\checkmark$ & & $\checkmark$ & & & & $\checkmark$ & & & $\checkmark$ & 11 \\
\hline 23 & Hoisting equipment & $\begin{array}{ll} \\
\end{array}$ & $\begin{array}{l} \\
\end{array}$ & $\checkmark$ & $\checkmark$ & $\checkmark$ & $\checkmark$ & & $\checkmark$ & $\checkmark$ & & $\sqrt{ }$ & & & & & & & $\checkmark$ & & & & & & $\sqrt{ }$ & & & $\checkmark$ & 12 \\
\hline 24 & In-house capability & $\begin{array}{ll}\checkmark \\
\end{array}$ & $\begin{array}{ll}\checkmark \\
\end{array}$ & $\begin{array}{ll}\checkmark \\
\end{array}$ & & $\checkmark$ & $\checkmark$ & $\checkmark$ & $\checkmark$ & & & & & & & $\checkmark$ & $\sqrt{ }$ & $\checkmark$ & $\checkmark$ & $\checkmark$ & & $\checkmark$ & & & $\checkmark$ & & & $\checkmark$ & 15 \\
\hline 25 & FWS sustainability & & & & & & & & & & & & & & & & $\checkmark$ & & & & $\begin{array}{ll} \\
\end{array}$ & & & & & $\checkmark$ & $\sqrt{ }$ & $\checkmark$ & 5 \\
\hline 26 & FWS safety & & & & & & & & & & & & & & & $\checkmark$ & $\sqrt{ }$ & & & $\checkmark$ & $\checkmark$ & $\sqrt{ }$ & & $\sqrt{ }$ & & $\sqrt{ }$ & $\sqrt{ }$ & $\sqrt{ }$ & 9 \\
\hline 27 & FWS durability & & & & & & & & & & & & & & & $\checkmark$ & & $\checkmark$ & & $\checkmark$ & & $\checkmark$ & & & & $\checkmark$ & $\checkmark$ & $\checkmark$ & 7 \\
\hline 28 & FWS flexibility & & & & & & & & & & & & & & & $\checkmark$ & $\sqrt{ }$ & $\checkmark$ & & $\checkmark$ & $\checkmark$ & $\checkmark$ & & & & $\sqrt{ }$ & $\checkmark$ & $\checkmark$ & 9 \\
\hline 29 & FWS compatibility & & & & & & & & & & & & & & & $\checkmark$ & & & & $\checkmark$ & & $\checkmark$ & & & & & & $\checkmark$ & 4 \\
\hline 30 & FWS complexity & & & & & & & & & & & & & & & & & $\sqrt{ }$ & & & $\begin{array}{l} \\
\end{array}$ & & & & & & & $\checkmark$ & 3 \\
\hline 31 & FWS weight & & & & & & & & & & & & & & & $\sqrt{ }$ & & $\checkmark$ & & $\checkmark$ & & $\sqrt{ }$ & & & & $\checkmark$ & $\checkmark$ & $\checkmark$ & 7 \\
\hline 32 & FWS size & & & & & & & & & & & & & & & & & $\checkmark$ & & & & & & & & & & $\checkmark$ & 2 \\
\hline 33 & FWF technical support & & & & & & & & & & & & & & & & & $\checkmark$ & & & & & & $\sqrt{ }$ & & $\begin{array}{l} \\
\end{array}$ & $\sqrt{ }$ & $\checkmark$ & 5 \\
\hline 34 & FWF logistical support & \begin{tabular}{|l} 
\\
\end{tabular} & \begin{tabular}{|l} 
\\
\end{tabular} & $\begin{array}{ll} \\
\end{array}$ & & $\checkmark$ & $\checkmark$ & $\checkmark$ & $\checkmark$ & & & & & & & $\checkmark$ & & & $\begin{array}{ll} \\
\end{array}$ & $\checkmark$ & $\begin{array}{l} \\
\end{array}$ & $\checkmark$ & & & $\checkmark$ & $\checkmark$ & $\checkmark$ & $\checkmark$ & 16 \\
\hline 35 & FWF BIM support & & & & & & & & & & & & & & & & $\sqrt{ }$ & & & & & & & & & & & $\checkmark$ & 2 \\
\hline
\end{tabular}

Figure 2. FWS selection criteria in building construction projects (adapted from [10]).

The questionnaire was designed using Google Forms, which is a prominent and frequently used online survey system in managerial sciences [59,67]. Then, the questionnaire was reviewed by three experts, who have more than 20 years of international experience in both technical and administrative aspects of formwork engineering, before distributing the questionnaires. The experts were asked to validate the identified FWS selection criteria and approve the appropriateness of the questionnaire structure and questions. The suggestions of these experts related to the applicability of the FWS selection criteria, and the appropriateness of the questionnaire's structure and questions were carefully considered by the authors. Necessary revisions were made in the questionnaire when applicable. The questions were kept simple, and leading questions were avoided. The wording and the order of the questions were checked by the authors and these experts in order to minimize the response bias. 


\subsection{Data Collection}

The targeted respondents of this study included the construction professionals, who may be in charge of selecting the FWSs in the Turkish building construction sector. These professionals may be company owners (CO), project managers (PM), construction managers $(\mathrm{CM})$, site engineers (SE), planning engineers (PL), procurement engineers (PR), technical office engineers (TO), and formwork design and/or formwork sales engineers (FD/FSL). Moreover, these construction professionals may be the employees of companies specialized in different fields (i.e., stakeholder groups), such as project management service (PMS), engineering and design (ENG/DSG), formwork and scaffolding (FW/SCF), and general and/or sub-contractor (GC/SC). It should be noted that COs may own either PMS, ENG/DSG, FW/SCF, or GC/SC companies.

The population number in this study is extracted from the statistics produced by Turkish Statistical Institute (TUIK), which indicate that the number of paid employees in the building construction sector in Turkey is 890,000 [68]. In this study, random sampling technique, which is widely used in the construction management field and where the sample is randomly selected from the population based on non-zero probability, was used for selecting the participants [69]. This sampling technique is found to be effective as the sample represents the population accurately by avoiding any voluntary response bias [70].

The sample size formula (Equation (1)) [71] is a widely used equation to determine sample sizes in the field of construction management [72]. Utilizing the sample size formula, with a population size of 890,000 , a significance level of $\alpha=0.05$, a sample proportion of 0.5 , and a $7 \%$ margin of error, the required sample size was determined to be $n=196$.

$$
n_{\text {req }}=\frac{Z^{2} p(1-p)}{e^{2}}=\frac{1.96^{2} \times 0.5 \times 0.5}{(0.07)^{2}}=196
$$

where $n_{\text {req }}$ is the required sample size, $Z$ is the critical value of the normal distribution at $\alpha / 2, p$ is the sample proportion (i.e., expected prevalence), and $e$ is the margin of error (i.e., precision). Although $5 \%$ margin of error is commonly used, researchers may increase this value depending on the characteristics of the research [73] up to 9\% [68]. Margin of error higher than $5 \%$ was adopted by researchers in the field of construction management $[69,72]$.

The survey link was delivered electronically to over 2500 respondents in Turkey through the Union of Chambers of Turkish Engineers and Architects (UCTEA) and the Association of Formwork and Scaffold Manufacturers (IKSD). A total of 244 responses were obtained, and, out of 244 responses, 22 questionnaires were eliminated due to invalid responses (i.e., all FWS selection criteria were ranked with the same importance level), resulting in a total of 222 valid questionnaires with a response rate of $9 \%$ for data analysis. Since a sample size of $n=222$ is higher than the required sample size of 196, the sample size was found to be satisfactory for data analysis. In general, response rates can be low in questionnaires related to construction management studies [74,75]. For example, Fahmy et al. [76] and Goh and Abdul-Rahman [77] reported response rates $4.1 \%$ and $7.5 \%$, respectively. In addition, the relatively low response rates may be attributed to the fact that FWS selection is dependent on the experience of decision-makers in the field of formwork engineering, which may be not as common as other types of construction experience. When compared to previous related studies on FWS selection criteria, this sample size may be regarded as acceptable $[17,30]$

The data from the questionnaire were grouped into certain groups of "professional titles" based on the respondents' similar demographic backgrounds. In building construction projects, for instance, since the $\mathrm{PM}, \mathrm{CM}$, and $\mathrm{SE}$ usually execute the project as employees of the contractor (e.g., GC/SC group) on-site, they may be considered an on-site construction team (i.e., PM/CM/SE group and/or GC/SC group). In contrast, the PL, $\mathrm{PR}$, and TO engineers can be considered technical and administrative support, and thus an off-site team (i.e., PL/PR/TO group) [78]. Moreover, in building construction projects, the organisational structure typically separates the off-site design team (i.e., TO) from 
the on-site construction team [79]. The demographic information of the respondents and respondents' company are provided in Tables A1 and A2, respectively.

In addition to the demographic background information, the respondents were asked to provide quantitative information on the "building structural parameters" (e.g., typical building floor area, typical building floor-to-height) of the construction project in which the respondents are presently working. The information on the "building structural parameters" is shown in Table A3.

\subsection{Data Analysis}

The valid questionnaire data were stored and analysed with the Statistical Package for Social Sciences (IBM SPSS, Version 28.0). In general, non-parametric tests are used to infer the population distribution of a known sample of data with an unknown distribution [80]. In addition, non-parametric tests can be used when the independently sampled groups have unequal sizes of respondents [81]. Since the data from the questionnaire were collected on an ordinal measurement scale (e.g., Likert scale) and had a non-normal distribution with unequal sizes of independently sampled groups, non-parametric statistical tests were employed to analyse the data [82]. A 95\% confidence level (or 5\% significance level) was considered in the non-parametric test utilized in this study. The following are brief descriptions of the methods and statistical tests utilized in this study:

\subsubsection{Reliability and Validity Analysis of the Questionnaire}

The reliability and validity of a questionnaire can be used to analyse its characteristics as a measuring instrument [83]. Reliability refers to the degree to which a measurement instrument is biased or conveys accurate and consistent results [84]. Cronbach's $\alpha$ is an internal consistency measure that is commonly used in reliability testing [82,85]. This study used Cronbach's $\alpha$ coefficient to test the reliability of the questionnaire data, and it was determined using Equation (2):

$$
\alpha=\frac{k}{k-1}\left(1-\frac{\sum \sigma_{i}^{2}}{\sigma_{x}^{2}}\right)
$$

where $k$ is the total number of items, $\sigma_{i}^{2}$ is the item variance, and $\sigma_{X}^{2}$ is the variance of the sum of scores. The Cronbach's $\alpha$ coefficient was calculated for the 35 FWS selection criteria. Cronbach's $\alpha$ coefficient values typically range from 0 to 1 , with a value larger than 0.70 being considered acceptable [86]. The Cronbach's $\alpha$ coefficient for all 35 FWS selection criteria is 0.973 (i.e., $\alpha>0.70$ ), which is considered to indicate excellent internal consistency in the dataset [87].

Validity is the extent to which research is accurate [88]. Content validity and construct validity are two of the most prominent types of validity in business research $[83,84]$. Content validity can be provided by developing the questionnaire based on previous studies [59]. Hence, an extensive literature review on the FWS selection criteria provides content validity in this study's questionnaire. In addition, the questionnaire was distributed after a review by three experts in formwork engineering, ensuring the questionnaire's content validity.

Construct validity is a method of determining whether a questionnaire instrument measures what it intends to measure [89]. To ensure construct validity, the Kaiser-MeyerOlkin (KMO) test and Bartlett's test of sphericity were used to evaluate sampling adequacy and justify that the data obtained were adequate for succeeding data analysis. For further data analysis, Kaiser [90] suggests a KMO value larger than 0.60 , but some studies indicate that a KMO value larger than 0.50 may also be acceptable [91]. The KMO test results revealed a value of 0.942 for the 35 FWS selection criteria, which indicates adequate intercorrelations. The Bartlett's test of sphericity results provided a chi-square value of 6966.708 , and the corresponding level of significance is $p=0.000$, which demonstrates that 
the correlation matrix is not an identity matrix [92]. Consequently, the questionnaire data confirm construct validity and are acceptable for further data analysis.

\subsubsection{Mean Score Analysis}

The purpose of mean score analysis in quantitative research is to rank the relative importance of factors [93], such as the FWS selection criteria. This method is commonly used in the field of construction management to rank the relative importance levels of different factors among respondent groups [82]. Hence, to answer the research question Q1, this study uses the mean score analysis to measure the relative importance of the FWS selection criteria of the respondents. First, the overall ranking of the 35 FWS selection criteria were calculated for 222 respondents. Then, based on the demographic results of the questionnaire, the rankings of the FWS selection criteria were categorized into two parts, with each part consisting of four groups of respondents: part (a) "professional title" of respondents (CO, PM/CM/SE, PL/PR/TO, and FD/FSL) and part (b) "field of specialization" of the companies (PMS, ENG/DSG, FW/SCF, and GC/SC). The mean score for each FWS selection criterion in each group was calculated and compared to determine how different respondent groups perceived their importance.

\subsubsection{Development of the Hypotheses}

Based on the research questions (i.e., Q2, Q3, and Q4) explicitly described in the Literature Review section, the following null hypotheses for FWS selection criteria in building construction projects were developed:

Hypothesis 1 (H1). No significant differences exist in FWS selection criteria in building construction projects among the "professional titles" of the respondents.

Hypothesis 2 (H2). No significant differences exist in FWS selection criteria in building construction projects among the "field of specialization" of the respondents' companies.

Hypothesis 3 (H3). The changes in the values of the "building structural parameters" have no significant effects on the importance levels of the FWS selection criteria in building construction projects.

Hypotheses 1 and 2 are intended to compare the level of importance of FWS selection criteria among different demographic backgrounds, whereas Hypothesis 3 is intended to compare the differences in the importance levels of the FWS selection criteria according to the changes in the values of the "building structural parameters".

\subsubsection{Validation of the Hypotheses (Kruskal-Wallis Test and Mann-Whitney U Test)}

The main objective of this study is to investigate and compare the perspectives and perceptions of construction professionals and stakeholder groups as well as the effects of "building structural parameters" towards FWS selection criteria in building construction projects in Turkey. Therefore, the ranking perceptions of the identified groups can be studied by means of non-parametric statistical tests applicable to ordinal data. In general, the following two hypotheses are tested for each identified group:

Hypothesis $\mathbf{0}\left(\mathbf{H}_{\mathbf{0}}\right)$. Null hypothesis: there is no difference between the groups; therefore, they possess the same mean (e.g., $H_{0}: C O=P M / C M / S E=P L / P R / T O=F D / F S L$ ).

Hypothesis $\mathbf{1}\left(\mathbf{H}_{\mathbf{1}}\right)$. Alternative hypothesis: there is a difference between the groups; therefore, there exist different means (e.g., $H_{1}: C O \neq P M / C M / S E=P L / P R / T O=F D / F S L$ ).

The Kruskal-Wallis test can be used for evaluating Likert scale responses (i.e., ordinal data) and in circumstances when the assumption of normality is unjustified [94]. In addition, this test is utilized to determine whether there are any significant mean differences 
among three or more independently sampled groups $[95,96]$. This test statistic has a distinct distribution regarded as the chi-square distribution [97]. The Kruskal-Wallis formula is shown in Equation (3):

$$
K W=\frac{12}{n(n+1)}\left(\sum \frac{R_{i}^{2}}{n_{i}}\right)-3(n+1)
$$

where $n$ is the total sample size, $n_{i}$ is the sample size of the $i$-th group, and $R_{i}$ is the sum of the ranks of the $i$-th group.

In the context of this study, first, the Kruskal-Wallis test was conducted to test Hypothesis 1 and Hypothesis 2 and to determine which, if any, of the FWS selection criteria had statistically significant difference among the four response groups in each category. Then, Mann-Whitney U test (Wilcoxon rank) was utilized to conduct a pairwise comparison among two response groups [98]. In addition, only the Mann-Whitney U test was performed to test Hypothesis 3 as there were only two response groups in each "building structural parameter" category. A 0.05 (5\%) level of significance was considered to represent a statistically significant difference in ranking among the groups for both tests.

3.4.5. Determination of Critical FWS Selection Criteria (Kendall's Concordance Analysis $(\mathrm{W})$ and Spearman's Rank Correlation (R))

The combined perception of all respondent groups can be used to determine the critical FWS selection criteria in building construction projects (i.e., research question Q5). For this purpose, initially, Kendall's concordance analysis is conducted to determine the degree of agreement on rankings within a group of respondents [99]. Kendall's coefficient of concordance $W$ value ranges from 0 to 1 , with 1 indicating total agreement, 0 indicating no agreement, and 0.05 indicating general agreement within the group on the ranking of specified variables [100]. An acceptable agreement is found among a group of respondents if the Kendall's coefficient of concordance $W$ value is significant at the level of 0.05 [101]. The results of the Kendall's concordance analysis revealed a $W$ value of 0.147 and a significance level of less than 0.001 for the rankings of the 35 FWS selection criteria among all respondents. Thus, there was a significant agreement among all respondents' groups.

The correlations among the identified groups were determined using Spearman's rank correlation, a non-parametric test that is widely used to determine the degree of agreement between two groups of ranking $[93,102]$. The Spearman's rank correlation coefficient $\rho$ can be calculated using Equation (4) [103]:

$$
\rho=1-\frac{6 \sum D^{2}}{n\left(n^{2}-1\right)}
$$

where $\rho$ is the Spearman's rank correlation coefficient, $D$ is the difference between ranks assigned to each factor (e.g., FWS selection criteria), and $n$ is the number of respondents. The Spearman's rank correlation coefficient ranges between +1 and -1 , where -1 represents perfect negative relationship (disagreement), 0 signifies no correlation, and +1 denotes perfect positive relationship (agreement) [104]. The Spearman's rank correlation coefficients were calculated among pairs of groups to demonstrate the agreement among them. Subsequently, the top five ranked FWS selection criteria, previously identified using the mean score analysis, were compared among the different groups to determine the critical FWS selection criteria.

\section{Results}

This section provides the results of the mean score analysis, Kruskal-Wallis test, Mann-Whitney U test, and Spearman's rank correlation. 


\subsection{Results of Mean Score Analysis}

Mean score analysis is a method for determining the relative importance levels among several factors $[105,106]$. In addition, using the findings of a mean score analysis, the similarities in ranking among different groups of respondents can be identified [107]. Hence, in this study, the relative importance levels of the FWS selection criteria were measured using mean scores (i.e., mean ranking). Initially, for the 222 respondents, the overall ranking of the $35 \mathrm{FWS}$ selection criteria was calculated based on the mean score of each FWS selection criterion. Then, utilizing mean score analysis, the rankings of the FWS selection criteria of different groups under the "professional title" category and the "field of specialization" category were determined. The results of the mean score analysis for the "professional title" and "field of specialization" categories are shown in Tables 1 and 2 , respectively.

Table 1. Mean score analysis of "professional title" of respondents.

\begin{tabular}{|c|c|c|c|c|c|c|c|c|c|c|}
\hline \multirow{3}{*}{ ID No. } & \multirow{2}{*}{\multicolumn{2}{|c|}{$\begin{array}{l}\text { Overall Respondents } \\
\qquad(\mathrm{N}=222)\end{array}$}} & \multicolumn{8}{|c|}{ Professional Title of Respondents } \\
\hline & & & \multicolumn{2}{|c|}{$\mathrm{CO}(\mathrm{N}=54)$} & \multicolumn{2}{|c|}{$\mathrm{PM} / \mathrm{CM} / \mathrm{SE}(\mathrm{N}=\mathbf{8 1})$} & \multicolumn{2}{|c|}{$\mathrm{PL} / \mathrm{PR} / \mathrm{TO}(\mathrm{N}=42)$} & \multicolumn{2}{|c|}{ FD/FSL $(\mathrm{N}=45)$} \\
\hline & Mean & Rank & Mean & Rank & Mean & Rank & Mean & Rank & Mean & Rank \\
\hline ID1 & 3.847 & 4 & 3.648 & 10 & 3.839 & 2 & 3.428 & 9 & 4.488 & 1 \\
\hline ID2 & 3.846 & 5 & 3.722 & 7 & 3.765 & 6 & 3.547 & 5 & 4.422 & 2 \\
\hline ID3 & 3.495 & 13 & 3.481 & 15 & 3.407 & 15 & 3.285 & 13 & 3.866 & 14 \\
\hline ID4 & 3.648 & 10 & 3.425 & 16 & 3.604 & 9 & 3.476 & 7 & 4.155 & 9 \\
\hline ID5 & 2.891 & 31 & 2.666 & 32 & 2.839 & 31 & 2.928 & 19 & 3.222 & 28 \\
\hline ID6 & 3.869 & 3 & 3.888 & 3 & 3.765 & 5 & 3.571 & 3 & 4.311 & 4 \\
\hline ID7 & 3.563 & 12 & 3.759 & 6 & 3.518 & 13 & 3.190 & 16 & 3.755 & 16 \\
\hline ID8 & 3.162 & 23 & 3.111 & 25 & 3.13 & 21 & 2.714 & 24 & 3.688 & 18 \\
\hline ID9 & 3.486 & 15 & 3.537 & 14 & 3.2469 & 19 & 3.309 & 10 & 4.022 & 11 \\
\hline ID10 & 3.662 & 9 & 3.592 & 12 & 3.604 & 8 & 3.571 & 4 & 3.933 & 13 \\
\hline ID11 & 3.189 & 21 & 3.259 & 19 & 3.098 & 25 & 2.952 & 18 & 3.488 & 26 \\
\hline ID12 & 3.905 & 2 & 3.870 & 5 & 3.802 & 4 & 3.738 & 1 & 4.288 & 6 \\
\hline ID13 & 3.486 & 16 & 3.703 & 9 & 3.4198 & 14 & 3.214 & 15 & 3.600 & 21 \\
\hline ID14 & 3.603 & 11 & 3.722 & 8 & 3.543 & 11 & 3.309 & 11 & 3.844 & 15 \\
\hline ID15 & 2.675 & 33 & 2.666 & 33 & 2.666 & 34 & 2.309 & 33 & 3.044 & 33 \\
\hline ID16 & 2.455 & 35 & 2.296 & 35 & 2.567 & 35 & 2.285 & 34 & 2.600 & 35 \\
\hline ID17 & 2.648 & 34 & 2.444 & 34 & 2.740 & 33 & 2.333 & 32 & 3.022 & 34 \\
\hline ID18 & 3.950 & 1 & 4.018 & 2 & 3.864 & 1 & 3.642 & 2 & 4.311 & 5 \\
\hline ID19 & 2.959 & 30 & 2.944 & 30 & 2.950 & 30 & 2.809 & 23 & 3.133 & 30 \\
\hline ID20 & 2.968 & 29 & 3.018 & 28 & 3.024 & 29 & 2.642 & 27 & 3.111 & 31 \\
\hline ID21 & 3.495 & 14 & 3.555 & 13 & 3.530 & 12 & 3.238 & 14 & 3.600 & 22 \\
\hline ID22 & 3.842 & 6 & 4.166 & 1 & 3.580 & 10 & 3.547 & 6 & 4.200 & 8 \\
\hline ID23 & 3.783 & 8 & 3.629 & 11 & 3.814 & 3 & 3.452 & 8 & 4.222 & 7 \\
\hline ID24 & 3.243 & 20 & 3.166 & 21 & 3.333 & 16 & 2.857 & 20 & 3.533 & 25 \\
\hline ID25 & 3.175 & 22 & 3.407 & 17 & 3.0741 & 28 & 2.619 & 28 & 3.600 & 23 \\
\hline ID26 & 3.261 & 19 & 3.148 & 23 & 3.321 & 17 & 2.857 & 21 & 3.666 & 19 \\
\hline ID27 & 3.837 & 7 & 3.888 & 4 & 3.753 & 7 & 3.309 & 12 & 4.422 & 3 \\
\hline ID28 & 3.351 & 17 & 3.240 & 20 & 3.259 & 18 & 3.023 & 17 & 3.955 & 12 \\
\hline ID29 & 3.090 & 26 & 3.296 & 18 & 3.098 & 24 & 2.714 & 25 & 3.177 & 29 \\
\hline ID30 & 3.067 & 28 & 3.037 & 27 & 3.098 & 27 & 2.690 & 26 & 3.400 & 27 \\
\hline ID31 & 3.130 & 24 & 3.166 & 22 & 3.098 & 26 & 2.595 & 29 & 3.644 & 20 \\
\hline ID32 & 3.099 & 25 & 3.074 & 26 & 3.123 & 22 & 2.547 & 30 & 3.600 & 24 \\
\hline ID33 & 3.279 & 18 & 3.129 & 24 & 3.172 & 20 & 2.833 & 22 & 4.066 & 10 \\
\hline ID34 & 3.085 & 27 & 2.981 & 29 & 3.111 & 23 & 2.476 & 31 & 3.733 & 17 \\
\hline ID35 & 2.752 & 32 & 2.944 & 31 & 2.790 & 32 & 2.071 & 35 & 3.088 & 32 \\
\hline
\end{tabular}


Table 2. Mean score analysis of "field of specialization" of respondents' company.

\begin{tabular}{|c|c|c|c|c|c|c|c|c|c|c|}
\hline \multirow{3}{*}{ ID No. } & \multirow{2}{*}{\multicolumn{2}{|c|}{$\begin{array}{l}\text { Overall Respondents } \\
\qquad(\mathrm{N}=\mathbf{2 2 2})\end{array}$}} & \multicolumn{8}{|c|}{ Field of Specialization of Respondents' Company } \\
\hline & & & \multicolumn{2}{|c|}{ PMS (N = 66) } & \multicolumn{2}{|c|}{ ENG/DSG $(N=43)$} & \multicolumn{2}{|c|}{ FW/SCF $(N=48)$} & \multicolumn{2}{|c|}{$\mathrm{GC} / \mathrm{SC}(\mathrm{N}=65)$} \\
\hline & Mean & Rank & Mean & Rank & Mean & Rank & Mean & Rank & Mean & Rank \\
\hline ID1 & 3.846 & 4 & 4.000 & 1 & 3.581 & 12 & 4.4375 & 1 & 3.430 & 9 \\
\hline ID2 & 3.846 & 5 & 3.924 & 2 & 3.674 & 8 & 4.3750 & 3 & 3.492 & 7 \\
\hline ID3 & 3.495 & 13 & 3.545 & 11 & 3.488 & 15 & 3.8750 & 15 & 3.169 & 16 \\
\hline ID4 & 3.648 & 10 & 3.651 & 9 & 3.441 & 16 & 4.1250 & 9 & 3.430 & 10 \\
\hline ID5 & 2.891 & 31 & 2.787 & 31 & 2.767 & 31 & 3.1667 & 29 & 2.876 & 26 \\
\hline ID6 & 3.869 & 3 & 3.742 & 7 & 3.883 & 5 & 4.3542 & 4 & 3.630 & 4 \\
\hline ID7 & 3.563 & 12 & 3.515 & 12 & 3.581 & 13 & 3.7917 & 16 & 3.430 & 11 \\
\hline ID8 & 3.162 & 23 & 3.151 & 22 & 3.116 & 21 & 3.7292 & 18 & 2.784 & 28 \\
\hline ID9 & 3.486 & 15 & 3.318 & 16 & 3.697 & 7 & 4.0625 & 11 & 3.092 & 19 \\
\hline ID10 & 3.662 & 9 & 3.590 & 10 & 3.907 & 3 & 4.0000 & 12 & 3.323 & 13 \\
\hline ID11 & 3.189 & 21 & 3.106 & 25 & 3.279 & 17 & 3.4792 & 26 & 3.000 & 21 \\
\hline ID12 & 3.905 & 2 & 3.772 & 5 & 4.000 & 2 & 4.2917 & 6 & 3.692 & 2 \\
\hline ID13 & 3.486 & 16 & 3.333 & 15 & 3.558 & 14 & 3.6250 & 20 & 3.492 & 8 \\
\hline ID14 & 3.603 & 11 & 3.484 & 13 & 3.604 & 10 & 3.8958 & 14 & 3.507 & 6 \\
\hline ID15 & 2.675 & 33 & 2.666 & 33 & 2.581 & 34 & 3.0208 & 32 & 2.492 & 34 \\
\hline ID16 & 2.455 & 35 & 2.424 & 34 & 2.627 & 33 & 2.5833 & 35 & 2.276 & 35 \\
\hline ID17 & 2.648 & 34 & 2.363 & 35 & 2.697 & 32 & 3.0208 & 33 & 2.630 & 32 \\
\hline ID18 & 3.950 & 1 & 3.909 & 3 & 3.907 & 4 & 4.3125 & 5 & 3.753 & 1 \\
\hline ID19 & 2.959 & 30 & 3.151 & 23 & 3.023 & 26 & 3.1042 & 30 & 2.615 & 33 \\
\hline ID20 & 2.968 & 29 & 3.075 & 26 & 3.139 & 18 & 3.0833 & 31 & 2.661 & 31 \\
\hline ID21 & 3.495 & 14 & 3.469 & 14 & 3.651 & 9 & 3.6250 & 21 & 3.323 & 14 \\
\hline ID22 & 3.842 & 6 & 3.878 & 4 & 4.046 & 1 & 4.1875 & 8 & 3.415 & 12 \\
\hline ID23 & 3.783 & 8 & 3.697 & 8 & 3.767 & 6 & 4.2292 & 7 & 3.553 & 5 \\
\hline ID24 & 3.243 & 20 & 3.212 & 20 & 3.093 & 22 & 3.5000 & 25 & 3.184 & 15 \\
\hline ID25 & 3.175 & 22 & 3.197 & 21 & 3.023 & 27 & 3.5625 & 23 & 2.969 & 22 \\
\hline ID26 & 3.261 & 19 & 3.227 & 19 & 3.023 & 28 & 3.6875 & 19 & 3.138 & 17 \\
\hline ID27 & 3.837 & 7 & 3.772 & 6 & 3.604 & 11 & 4.3958 & 2 & 3.646 & 3 \\
\hline ID28 & 3.351 & 17 & 3.272 & 17 & 3.139 & 19 & 3.9583 & 13 & 3.123 & 18 \\
\hline ID29 & 3.090 & 26 & 3.151 & 24 & 3.093 & 23 & 3.2083 & 28 & 2.938 & 24 \\
\hline ID30 & 3.067 & 28 & 3.060 & 27 & 2.953 & 30 & 3.3750 & 27 & 2.923 & 25 \\
\hline ID31 & 3.130 & 24 & 2.924 & 30 & 3.069 & 24 & 3.6042 & 22 & 3.030 & 20 \\
\hline ID32 & 3.099 & 25 & 2.954 & 29 & 3.046 & 25 & 3.5417 & 24 & 2.953 & 23 \\
\hline ID33 & 3.279 & 18 & 3.242 & 18 & 3.139 & 20 & 4.0833 & 10 & 2.815 & 27 \\
\hline ID34 & 3.085 & 27 & 3.060 & 28 & 2.976 & 29 & 3.7708 & 17 & 2.676 & 30 \\
\hline ID35 & 2.752 & 32 & 2.757 & 32 & 2.558 & 35 & 3.0000 & 34 & 2.692 & 29 \\
\hline
\end{tabular}

According to the results of the mean score analysis for the overall respondents (Table 1), "initial cost of the FWS" (ID 18), "speed of construction" (ID 12), "degree of repetition of the FWS" (ID 6), "type of structural slab" (ID 1), and "type of structural lateral loads-supporting system" (ID 2) were ranked as the top five FWS selection criteria in descending order. All four groups under the "field of specialization" category (e.g., $\mathrm{CO}, \mathrm{PM} / \mathrm{CM} / \mathrm{SE}, \mathrm{PM} / \mathrm{CM} / \mathrm{SE}, \mathrm{PL} / \mathrm{PR} / \mathrm{TO}$, and FD/FSL) ranked "degree of repetition of the FWS" (ID 6) and "initial cost of the FWS" (ID 18) among the top five FWS selection criteria. In addition, "speed of construction" (ID 12) was ranked among the top five FWS selection criteria by the CO, PM/CM/SE, and PL/PR/TO groups. The CO and FD/FSL groups ranked "FWS durability" (ID 27), the PL/PR/TO and FD/FSL groups ranked "type of structural lateral loads-supporting system" (ID 2), and the PM/CM/SE and FD/FSL groups ranked "type of structural slab" (ID 1) among the top five FWS selection criteria in building construction projects. Furthermore, the $\mathrm{CO}$ group ranked "potential reuse of the FWS in other projects" (ID 22), the PM/CM/SE group ranked "hoisting equipment" (ID 23), and the PL/PR/TO group ranked "uniformity of building" (ID 10) among the top five FWS selection criteria. 
According to Table 2, all four groups under the "field of specialization" category (e.g., PMS, ENG/DSG, FW/SCF, and GC/SC) ranked "initial cost of the FWS" (ID 18) among the top five FWS selection criteria. Moreover, "degree of repetition of the FWS" (ID 6) and "speed of construction" (ID 12) were ranked among the top five FWS selection criteria by three groups under this category. The PMS and FW/SCF groups ranked "type of structural slab" (ID 1) and "type of structural lateral loads-supporting system" (ID 2), the PMS and ENG/DSG groups ranked "potential reuse of the FWS in other projects" (ID 22), and the FW/SCF and GC/SC groups ranked "FWS durability" (ID 27) among the top five FWS selection criteria in building construction projects. "Uniformity of building" (ID 10) and "hoisting equipment" (ID 23) were ranked only by the ENG/DSG group and GC/SC group, respectively, among the top five FWS selection criteria.

The mean score analysis revealed that the "initial cost of the FWS" (ID 18) was always ranked in each of the two categories and among all the groups (e.g., "professional title" of respondents and "field of specialization" of respondent's company) as the top five FWS selection criteria. In addition, nine (e.g., ID 1, ID2 ID 6, ID 10, ID12, ID 18, ID 22, ID 23, and ID27) out of the 35 FWS selection criteria were always ranked among the top five FWS selection criteria in one of the two categories. Although some FWS selection criteria were ranked similarly by all the groups, others were ranked differently, and some FWS selection criteria were only ranked among the top five for a certain group. In general, while similar ranking may suggest an agreement in the perspective and perception among various groups [104], variations in ranking indicate that there may be significant differences [82], thus disagreements, in the rankings for the FWS selection criteria. Hence, further analysis is necessary to evaluate the differences and similarities in the perspectives and perceptions of different groups regarding FWS selection criteria.

\subsection{Results of Kruskal-Wallis Test and Mann-Whitney U Test}

The Kruskal-Wallis test was used to evaluate Hypothesis 1 and Hypothesis 2, as well as to identify which of the FWS selection criteria resulted in a significant statistical difference between the four response groups in each category. The results of the KruskalWallis test are presented in Table 3. Specifically, significant statistical differences (e.g., $p<0.05$ ) in perception are observed in 16 and 13 out of the 35 FWS selection criteria for the "professional title" category and for the "field of specialization" category, respectively. Regarding Hypothesis 1, the null hypothesis (e.g., $\mathrm{H}_{0}$ ) may be rejected as there are a considerable number of FWS selection criteria with significant statistical differences (e.g., 16 out of 35 FWS selection criteria). Therefore, a relative difference in perception exists among the four groups under the "professional title" category in terms of the FWS selection criteria. The null hypothesis, in respect to Hypothesis 2, may also be rejected since 13 out of the 35 FWS selection criteria have shown significant statistical differences. In other words, the alternative hypothesis $\mathrm{H}_{1}$ is accepted for both hypotheses as the relative importance levels of the FWS selection criteria in building construction projects vary (e.g., there exist different means) according to the "professional title" and "field of specialization".

However, to determine which of the response groups and which of the 35 FWS selection criteria reflect differences in ranking, the Mann-Whitney U test can be used by conducting a pair-wise comparison across these groups $[98,107]$. Furthermore, to test Hypothesis 3, that the "building structural parameters" have no significant effects on the FWS selection criteria in building construction projects, the Mann-Whitney $U$ test is performed since each building structural parameter category involves only two response groups (Table A3). 
Table 3. Kruskal-Wallis test statistics for "professional title" and "field of specialization" categories.

\begin{tabular}{|c|c|c|c|}
\hline \multirow[b]{2}{*}{ ID No. } & \multirow[b]{2}{*}{ FWS Selection Criteria } & \multicolumn{2}{|c|}{$p$-Values of the Kruskal-Wallis Tests } \\
\hline & & $\begin{array}{c}\text { Asymp. Sig. } \\
\text { (Professional Title) }\end{array}$ & $\begin{array}{l}\text { Asymp. Sig. (Field of } \\
\text { Specialization) }\end{array}$ \\
\hline 1 & Type of structural slab & $0.002 *$ & $0.002 *$ \\
\hline 2 & Type of structural lateral loads-supporting system & $0.003 *$ & $0.002 *$ \\
\hline 3 & Total building height & 0.171 & 0.093 \\
\hline 4 & Variation in column/wall dimensions and location & $0.021 *$ & $0.016^{*}$ \\
\hline 5 & Variation in openings/inserts dimensions and location & 0.298 & 0.533 \\
\hline 6 & Degree of repetition of the FWS & $0.044 *$ & $0.024 *$ \\
\hline 7 & Number of floors & 0.201 & 0.456 \\
\hline 8 & Floor area & 0.015 * & 0.008 * \\
\hline 9 & Floor to floor height & $0.042 *$ & $0.002 *$ \\
\hline 10 & Uniformity of building & 0.632 & $0.038 *$ \\
\hline 11 & Type of concrete finish & 0.304 & 0.268 \\
\hline 12 & Speed of construction & 0.195 & 0.091 \\
\hline 13 & Labour quality & 0.378 & 0.658 \\
\hline 14 & Labour productivity & 0.549 & 0.499 \\
\hline 15 & Weather conditions & 0.093 & 0.287 \\
\hline 16 & Site access & 0.389 & 0.681 \\
\hline 17 & Size of site & 0.075 & 0.109 \\
\hline 18 & Initial cost of the FWS & 0.132 & 0.110 \\
\hline 19 & Transportation cost of the FWS & 0.805 & 0.262 \\
\hline 20 & Maintenance cost of the FWS & 0.407 & 0.246 \\
\hline 21 & Labour cost of the FWS & 0.646 & 0.493 \\
\hline 22 & Potential reuse of the FWS in other projects & $0.017^{*}$ & $0.018 *$ \\
\hline 23 & Hoisting equipment & $0.041 *$ & $0.026^{*}$ \\
\hline 24 & In-house capability & 0.131 & 0.603 \\
\hline 25 & FWS sustainability & $0.015 *$ & 0.180 \\
\hline 26 & FWS safety & 0.065 & 0.126 \\
\hline 27 & FWS durability & $<0.001 *$ & $0.002 *$ \\
\hline 28 & FWS flexibility & 0.003 * & $0.003 *$ \\
\hline 29 & FWS compatibility & 0.278 & 0.780 \\
\hline 30 & FWS complexity & 0.148 & 0.361 \\
\hline 31 & FWS weight & $0.004 *$ & 0.055 \\
\hline 32 & FWS size & $0.009 *$ & 0.118 \\
\hline 33 & FWF technical support & $<0.001 *$ & $<0.001 *$ \\
\hline 34 & FWF logistical support & $0.001 *$ & $0.002 *$ \\
\hline 35 & FWF BIM support & 0.019 * & 0.667 \\
\hline
\end{tabular}

* The Kruskal-Wallis test is significant at the 0.05 level.

First, the Mann-Whitney U test was performed for the "professional title" category. As there are four groups under this category, a total of six pair-wise comparisons were conducted. For each comparison, the null hypothesis was tested that no significant differences exist in the perception of the response groups for the 35 FWS selection criteria. The results of the Mann-Whitney U test for the "professional title" category are presented in Table 4. The Mann-Whitney $U$ test results show that there are only a few significant statistical differences (e.g., $p<0.05$ ) in the perception among the CO, PM/CM/SE, and $\mathrm{PL} / \mathrm{PR} / \mathrm{TO}$ groups regarding the FWS selection criteria (i.e., one out of thirty-five FWS selection criteria between the $\mathrm{CO}$ and $\mathrm{PM} / \mathrm{CM} / \mathrm{SE}$ groups). However, the pair-wise comparison of the FD/FSL group with the other three groups reveals a large number of FWS selection criteria with statistically significant differences. For instance, significant differences in the perception regarding FWS selection criteria exist in 11 out of the 35 between the $\mathrm{CO}$ and FD/FSL groups, 13 out of 35 between the PM/CM/SE and FD/FSL groups, and 23 out of 35 between the PL/PR/TO and FD/FSL groups. These findings suggest that formwork design and formwork sales engineering construction professionals may have a different perception and perspective on the significance of FWS selection criteria 
than other construction professionals. In addition, the results of the Mann-Whitney $\mathrm{U}$ test are consistent with the results of the Kruskal-Wallis test. In particular, differences in perceptions are found in both tests among the same FWS selection criteria (Tables 3 and 4), with some additional criteria demonstrating significant differences by pair-wise comparison between FD/FSL and other groups. Subsequently, the Mann-Whitney U test was carried out for the "field of specialization" of the respondent's company category and the results are presented in Table 5. As observed in the results for the "professional title" category, the Mann-Whitney U test findings for the "field of specialization" category indicate that there are only a few significant statistical differences (e.g., $p<0.05$ ) in the perception regarding the FWS selection criteria among three (e.g., PMS, ENG/DSG, and GC/SC groups) out of the four groups. On the other hand, a pair-wise comparison of the FW/SCF group with the other three groups reveals a large number of FWS selection criteria with statistically significant differences (i.e., 20 out of 35 FWS selection criteria between FW/SCF and GC/SC groups). As anticipated, construction professionals working in the field of formwork engineering (e.g., FD/FSL group) demonstrate similar perceptions with the companies involved in the same field (e.g., FW/SCF group). Moreover, these construction professionals and companies working in the field of formwork engineering show significant differences regarding FWS selection criteria with the other groups.

Table 4. Mann-Whitney U test statistics for "professional title" category.

\begin{tabular}{|c|c|c|c|c|c|c|}
\hline \multirow{2}{*}{$\begin{array}{l}\text { FWS Selection } \\
\text { Criteria ID No. }\end{array}$} & \multicolumn{6}{|c|}{ Asymp. Sig. (Two-Tailed) of Pairwise Comparison } \\
\hline & $\begin{array}{c}\mathrm{CO} \text { and } \\
\mathrm{PM} / \mathrm{CM} / \mathrm{SE}\end{array}$ & $\begin{array}{c}\text { CO and } \\
\text { PL/PR/TO }\end{array}$ & $\mathrm{CO}$ and FD/FSL & $\begin{array}{c}\mathrm{PM} / \mathrm{CM} / \mathrm{SE} \text { and } \\
\mathrm{PL} / \mathrm{PR} / \mathrm{TO}\end{array}$ & $\begin{array}{c}\mathrm{PM} / \mathrm{CM} / \mathrm{SE} \text { and } \\
\text { FD/FSL }\end{array}$ & $\begin{array}{c}\text { PL/PR/TO and } \\
\text { FD/FSL }\end{array}$ \\
\hline 1 & 0.388 & 0.543 & $<0.001 *$ & 0.154 & $0.007 *$ & $<0.001 *$ \\
\hline 2 & 0.744 & 0.768 & $<0.001 *$ & 0.547 & $0.001 *$ & $0.002 *$ \\
\hline 3 & 0.693 & 0.375 & 0.199 & 0.509 & 0.071 & $0.034 *$ \\
\hline 4 & 0.300 & 0.613 & $0.002 *$ & 0.780 & $0.019 *$ & $0.033 *$ \\
\hline 5 & 0.569 & 0.367 & 0.062 & 0.732 & 0.149 & 0.355 \\
\hline 6 & 0.728 & 0.175 & 0.109 & 0.278 & 0.046 * & $0.004^{*}$ \\
\hline 7 & 0.577 & 0.059 & 0.792 & 0.188 & 0.374 & 0.056 \\
\hline 8 & 0.741 & 0.133 & 0.027 * & 0.112 & 0.082 & 0.001 * \\
\hline 9 & 0.347 & 0.481 & 0.079 & 0.831 & 0.007 * & 0.027 * \\
\hline 10 & 0.853 & 0.991 & 0.232 & 0.868 & 0.296 & 0.291 \\
\hline 11 & 0.422 & 0.320 & 0.530 & 0.624 & 0.110 & 0.100 \\
\hline 12 & 0.957 & 0.891 & 0.062 & 0.791 & $0.040 *$ & 0.148 \\
\hline 13 & 0.218 & 0.133 & 0.720 & 0.488 & 0.438 & 0.249 \\
\hline 14 & 0.430 & 0.311 & 0.941 & 0.562 & 0.360 & 0.205 \\
\hline 15 & 0.890 & 0.194 & 0.193 & 0.104 & 0.159 & 0.014 * \\
\hline 16 & 0.186 & 0.838 & 0.269 & 0.220 & 0.925 & 0.233 \\
\hline 17 & 0.253 & 0.678 & $0.037^{*}$ & 0.132 & 0.329 & $0.016^{*}$ \\
\hline 18 & 0.510 & 0.241 & 0.229 & 0.490 & 0.057 & 0.030 * \\
\hline 19 & 0.894 & 0.644 & 0.564 & 0.531 & 0.662 & 0.308 \\
\hline 20 & 0.897 & 0.208 & 0.831 & 0.161 & 0.962 & 0.091 \\
\hline 21 & 0.991 & 0.290 & 0.957 & 0.267 & 0.895 & 0.270 \\
\hline 22 & 0.019 * & 0.028 * & 0.991 & 0.851 & $0.023 *$ & 0.031 * \\
\hline 23 & 0.325 & 0.731 & $0.011 *$ & 0.237 & 0.081 & 0.013 * \\
\hline 24 & 0.567 & 0.225 & 0.253 & 0.065 & 0.480 & 0.024 * \\
\hline 25 & 0.294 & 0.013 * & 0.361 & 0.112 & 0.049 * & $0.005^{*}$ \\
\hline 26 & 0.490 & 0.341 & 0.078 & 0.087 & 0.209 & $0.010 *$ \\
\hline 27 & 0.831 & 0.082 & 0.003 * & 0.126 & 0.002 * & $<0.001 *$ \\
\hline 28 & 0.787 & 0.398 & 0.003 * & 0.282 & 0.003 * & $0.001 *$ \\
\hline 29 & 0.536 & 0.056 & 0.652 & 0.175 & 0.900 & 0.131 \\
\hline 30 & 0.727 & 0.253 & 0.163 & 0.156 & 0.203 & $0.032 *$ \\
\hline 31 & 0.867 & 0.040 * & 0.070 & $0.045^{*}$ & 0.034 * & $<0.001 *$ \\
\hline 32 & 0.706 & 0.061 & $0.039 *$ & $0.040 *$ & 0.077 & $0.001 *$ \\
\hline 33 & 0.827 & 0.333 & $<0.001 *$ & 0.204 & $<0.001 *$ & $<0.001 *$ \\
\hline 34 & 0.530 & 0.110 & 0.009 * & 0.026 * & 0.019 * & $<0.001 *$ \\
\hline 35 & 0.697 & 0.008 * & 0.631 & 0.020 * & 0.383 & 0.004 * \\
\hline
\end{tabular}

* The Mann-Whitney U test is significant at the 0.05 level. 
Table 5. Mann-Whitney U test statistics for "field of specialization" category.

\begin{tabular}{|c|c|c|c|c|c|c|}
\hline \multirow{2}{*}{$\begin{array}{l}\text { FWS Selection } \\
\text { Criteria ID No. }\end{array}$} & \multicolumn{6}{|c|}{ Asymp. Sig. (Two-Tailed) of Pairwise Comparison } \\
\hline & $\begin{array}{l}\text { PMS and } \\
\text { FW/SCF }\end{array}$ & $\begin{array}{l}\text { PMS and } \\
\text { ENG/DSG }\end{array}$ & $\begin{array}{l}\text { PMS and } \\
\text { GC/SC }\end{array}$ & $\begin{array}{c}\text { ENG/DSG and } \\
\text { FW/SCF }\end{array}$ & $\begin{array}{c}\text { ENG/DSG and } \\
\text { GC/SC }\end{array}$ & $\begin{array}{c}\text { FW/SCF and } \\
\text { GC/SC }\end{array}$ \\
\hline 1 & 0.014 * & 0.357 & 0.055 & $0.013 *$ & 0.463 & $<0.001 *$ \\
\hline 2 & $0.006 *$ & 0.663 & 0.087 & 0.020 * & 0.391 & $<0.001 *$ \\
\hline 3 & 0.150 & 0.931 & 0.197 & 0.189 & 0.305 & $0.013 *$ \\
\hline 4 & 0.090 & 0.322 & 0.200 & 0.010 * & 0.899 & $0.002 *$ \\
\hline 5 & 0.169 & 0.982 & 0.720 & 0.283 & 0.798 & 0.255 \\
\hline 6 & $0.008 *$ & 0.468 & 0.671 & 0.102 & 0.325 & $0.005 *$ \\
\hline 7 & 0.272 & 0.758 & 0.551 & 0.479 & 0.448 & 0.117 \\
\hline 8 & $0.039 *$ & 0.904 & 0.142 & 0.051 & 0.251 & $<0.001 *$ \\
\hline 9 & $0.006^{*}$ & 0.141 & 0.353 & 0.337 & 0.023 * & $<0.001 *$ \\
\hline 10 & 0.241 & 0.403 & 0.183 & 0.749 & 0.024 * & $0.007^{*}$ \\
\hline 11 & 0.254 & 0.516 & 0.522 & 0.735 & 0.249 & $0.039 *$ \\
\hline 12 & 0.057 & 0.419 & 0.621 & 0.365 & 0.176 & $0.016^{*}$ \\
\hline 13 & 0.253 & 0.339 & 0.561 & 0.993 & 0.650 & 0.551 \\
\hline 14 & 0.165 & 0.464 & 0.926 & 0.689 & 0.544 & 0.186 \\
\hline 15 & 0.183 & 0.747 & 0.588 & 0.126 & 0.873 & 0.070 \\
\hline 16 & 0.604 & 0.576 & 0.603 & 0.984 & 0.308 & 0.302 \\
\hline 17 & $0.016^{*}$ & 0.256 & 0.233 & 0.271 & 0.890 & 0.149 \\
\hline 18 & 0.213 & 0.908 & 0.261 & 0.200 & 0.346 & 0.010 * \\
\hline 19 & 0.846 & 0.749 & 0.069 & 0.871 & 0.201 & 0.130 \\
\hline 20 & 0.869 & 0.752 & 0.100 & 0.724 & 0.101 & 0.137 \\
\hline 21 & 0.698 & 0.274 & 0.564 & 0.527 & 0.177 & 0.322 \\
\hline 22 & 0.221 & 0.287 & 0.076 & 0.969 & 0.018 * & 0.005 * \\
\hline 23 & 0.031 * & 0.572 & 0.362 & 0.170 & 0.195 & $0.002 *$ \\
\hline 24 & 0.267 & 0.766 & 0.945 & 0.253 & 0.877 & 0.265 \\
\hline 25 & 0.123 & 0.693 & 0.463 & 0.132 & 0.816 & 0.032 * \\
\hline 26 & 0.078 & 0.480 & 0.731 & 0.038 * & 0.722 & 0.048 * \\
\hline 27 & $0.005^{*}$ & 0.665 & 0.380 & 0.005 * & 0.770 & $<0.001 *$ \\
\hline 28 & $0.003 *$ & 0.711 & 0.688 & 0.006 * & 0.872 & $<0.001 *$ \\
\hline 29 & 0.869 & 0.972 & 0.401 & 0.871 & 0.545 & 0.335 \\
\hline 30 & 0.214 & 0.714 & 0.627 & 0.159 & 0.957 & 0.098 \\
\hline 31 & $0.008 *$ & 0.591 & 0.614 & 0.116 & 0.822 & $0.021 *$ \\
\hline 32 & $0.031 *$ & 0.752 & 0.974 & 0.171 & 0.648 & $0.023 *$ \\
\hline 33 & $<0.001 *$ & 0.797 & 0.107 & 0.001 * & 0.266 & $<0.001 *$ \\
\hline 34 & $0.006^{*}$ & 0.832 & 0.172 & 0.012 * & 0.301 & $<0.001$ * \\
\hline 35 & 0.461 & 0.634 & 0.750 & 0.248 & 0.702 & 0.321 \\
\hline
\end{tabular}

* The Mann-Whitney U test is significant at the 0.05 level.

Finally, Hypothesis 3, that the changes in the values of the "building structural parameters" have no significant effects on the importance levels of the FWS selection criteria in building construction projects, was tested using the Mann-Whitney U test. Each "building structural parameter" category (e.g., typical building floor area, typical building floorto-floor height, total area of building construction, and total building height) consists of two groups. Hence, a pair-wise comparison among the 35 FWS selection criteria was conducted, and the results are presented in Table A4. The findings of the Mann-Whitney $\mathrm{U}$ test indicate that the "typical building floor area" and "typical building floor-to-floor height" categories have an impact on only two out of the thirty-five FWS selection criteria with a significant statistical difference. Therefore, the null hypothesis (e.g., $\left.\mathrm{H}_{0}\right)$ cannot be rejected for these two categories. However, the "total area of building construction" and "total building height" categories show significant statistical differences for sixteen and nine out of the thirty-five FWS selection criteria, respectively. Hence, the null hypothesis may be rejected, and the alternative hypothesis $\mathrm{H} 1$ can be accepted for both categories. In particular, the findings for the "total area of building construction" category suggest that the relative importance level of FWS selection criteria may vary between small and/or medium (e.g., $<20,000 \mathrm{~m}^{2}$ ) and large (e.g., $>20,000 \mathrm{~m}^{2}$ ) building construction projects [20]. 
Furthermore, the relative importance level of FWS selection criteria may also vary between low-rise (e.g., < $36.5 \mathrm{~m}$ ) and mid and/or high-rise (e.g., > $36.5 \mathrm{~m}$ ) building construction projects [20].

\subsection{Results of Spearman's Rank Correlation (R)}

The Spearman's rank correlation coefficients (e.g., $\rho$ ) were calculated among pairs of groups for the "professional title" and "field of specialization" categories. The Spearman's rank correlation coefficients, the level of significance, and the degree of agreement among the respondent groups are presented in Tables 6 and 7 for both categories, respectively.

Table 6. Spearman's rank correlation test results for "professional title" category.

\begin{tabular}{cccc}
\hline Combination of Groups & $\rho$ & $\begin{array}{c}\text { Level of } \\
\text { Significance }\end{array}$ & $\begin{array}{c}\text { Degree of } \\
\text { Agreement }\end{array}$ \\
\hline CO and PM/CM/SE & $0.893^{* *}$ & $<0.001$ & Positive, High \\
CO and PL/PR/TO & $0.870^{* *}$ & $<0.001$ & Positive, High \\
CO and FD/FSL & $0.812^{* *}$ & $<0.001$ & Positive, High \\
PM/CM/SE and PL/PR/TO & $0.903^{* *}$ & $<0.001$ & Positive, Very High \\
PM/CM/SE and FD/FSL & $0.901^{* *}$ & $<0.001$ & Positive, Very High \\
PL/PR/TO and FD/FSL & $0.831^{* *}$ & $<0.001$ & Positive, High \\
\hline$*$ Correlation is significant at the 0.01 level (2-tailed). & &
\end{tabular}

Table 7. Spearman's rank correlation test results for "field of specialization" category.

\begin{tabular}{cccc}
\hline Combination of Groups & $\rho$ & $\begin{array}{c}\text { Level of } \\
\text { Significance }\end{array}$ & $\begin{array}{c}\text { Degree of } \\
\text { Agreement }\end{array}$ \\
\hline PMS and FW /SCF & $0.913^{* *}$ & $<0.001$ & Positive, Very High \\
PMS and ENG/DSG & $0.889^{* *}$ & $<0.001$ & Positive, High \\
PMS and GC/SC & $0.886^{* *}$ & $<0.001$ & Positive, High \\
ENG/DSG and FW/SCF & $0.810^{* *}$ & $<0.001$ & Positive, High \\
ENG/DSG and GC/SC & $0.831^{* *}$ & $<0.001$ & Positive, High \\
FW/SCF and GC/SC & $0.822^{* *}$ & $<0.001$ & Positive, High \\
\hline ** Correlation is significant at the 0.01 level (2-tailed). & &
\end{tabular}

** Correlation is significant at the 0.01 level (2-tailed).

The findings of the Spearman's rank correlation test indicate a significant (e.g., <0.01) positive and high level of agreement among all the groups in both categories. In addition, these results confirm the reliability of this study's findings [108]. Therefore, by using the top five FWS selection criteria among all the respondents from the mean score analysis results, the critical FWS selection criteria can be obtained.

\section{Discussion}

\subsection{Discussion Based on Mean Score Analysis}

The mean score analysis revealed that the (1) "type of structural slab", (2) "type of structural lateral loads-supporting system", (3) "degree of repetition of the FWS", (4) "uniformity of building", (5) "speed of construction", (6) "initial cost of the FWS", (7) "potential reuse of the FWS in other projects", (8) "hoisting equipment", and (9) "FWS durability" were always ranked among the top five FWS selection criteria in either the "professional title" or "field of specialization" category. On the other hand, some of these criteria were ranked differently among the four groups of respondents in each category.

In building construction projects, "type of structural slab", "type of structural lateral loads-supporting system", "degree of repetition of the FWS", and "uniformity of building" are criteria that are related to the structural design of the building [24]. Furthermore, the structural design and the selected FWS have a significant impact on the constructability of an RC building project [109]. Since there may be different types of structural slabs (e.g., one-way slab, two-way slab) and different types of structural lateral loads-supporting systems (e.g., rigid frame, shear wall, tube-in-tube), the design and selection of the FWS is 
highly dependent on these two criteria $[2,7,110]$. Formwork design is usually performed by formwork design or formwork sales engineers (i.e., FD/FSL group). In other words, employees of formwork and scaffolding companies (i.e., FW/SCF group), who are considered experts in the field of formwork engineering perform the design and detail activities of the FWS [16]. As expected, the FD/FSL group ranked the "type of structural slab" and "type of structural lateral loads-supporting system" first and second, respectively. The FW/SCF group ranked the "type of structural slab" and "type of structural lateral loads-supporting system" first and third, respectively. Moreover, some FWSs may be more difficult to adapt to significant changes in building structural design than others, particularly in buildings with a non-uniform structural design. Hence, the "uniformity of building" and "degree of repetition of the FWS" are interdependent criteria and should be considered in tandem [10]. In addition, these FWS selection criteria are among the most important criteria for the selection of the appropriate FWSs and are frequently cited in previous studies (see Figure 2). Consequently, these criteria are considered among the most significant FWS selection criteria by many construction professionals in their FWS decision-making process, which is consistent with the findings of the mean score analysis.

The "speed of construction" and "initial cost of the FWS" are two criteria that may have a significant impact on the time and cost performance of a building construction project [4]. Formwork-related activities may account for up to $75 \%$ of the total time spent on the construction of RC building structures [58]. The "speed of construction" is primarily affected by the floor cycle time $[20,110]$ and can be measured by the time it takes to erect and strip the FWS, place and cure the concrete, and transport the FWS to the next location. The erecting, stripping, and moving times may be dependent on the characteristics of the selected FWS [111]. On the other hand, the curing time of concrete depends on concreterelated parameters (e.g., type of concrete mixture, required concrete strength) and weather conditions [112]. In addition, the "labour productivity" of formwork-related activities can be affected by weather conditions [113]; therefore, it may have an impact on the "speed of construction" as well. The "speed of construction" was ranked among the top five FWS selection criteria by all the groups in the "field of specialization category" except the FW/SCF group. The "initial cost of the FWS" and "potential reuse of the FWS in other projects" are cost criteria, which may have a substantial impact on the cost performance of building construction projects. For instance, if the selected FWS can be modified and utilized in other projects, the initial investment in the FWS may be minimized over time [10]. It should be noted that, among the 35 FWS selection criteria, "potential reuse of the FWS in other projects" was ranked first by company owners (i.e., COs) since it may affect the long-term investment of the companies. Moreover, as formwork may account for up to $60 \%$ of the overall cost of an RC building project [8], the "initial cost of the FWS" should be considered as one of the most important criteria in the selection process of FWSs. Excluding the FD/FSL group, all the other respondent groups in the "professional title category" ranked the "initial cost of the FWS" first or second among all the FWS selection criteria. In addition, the general or sub-contractors (i.e., GC/SC group) under the "field of specialization" category ranked the "initial cost of the FWS" first since the FWS is usually purchased or rented by the contractors. Therefore, "speed of construction", "initial cost of the FWS", and "potential reuse of the FWS in other projects" are decisive criteria in the selection of FWSs, and, as anticipated, these criteria are ranked among the most important FWS selection criteria in all the respondents' categories.

The demand for "hoisting equipment" on the construction site regarding FWSs has been substantially decreased in recent years due to technological innovations in formwork engineering [40,114]. Modular lightweight FWSs (e.g., FWSs consisting of plastic or aluminium material components) or self-climbing FWSs do not require crane equipment since they can be transported manually by hand or lifted automatically utilizing hydraulic systems [10,115]. However, traditional FWSs (e.g., FWSs consisting of timber material components) or industrial FWSs composed of heavy structural components (e.g., FWSs consisting of steel material components) are still commonly used in the building construction 
industry [21]. The majority of these FWSs necessitate the presence of "hoisting equipment" on the construction site. However, this criterion was only ranked among the top five FWS selection criteria by the PM/CM/SE group and the GC/SC group. As noted earlier, the $\mathrm{PM} / \mathrm{CM} / \mathrm{SE}$ and GC/SC groups execute the project as on-site construction teams [78]. Thus, to plan and ensure the availability of "hoisting equipment" on the construction site is a task usually performed by these two groups. As a result, the availability of "hoisting equipment" is an essential criterion for the PM/CM/SE and the GC/SC groups in the selection of FWSs.

"FWS durability", one of the FWS's characteristics, is regarded among the top five FWS selection criteria by the CO and FD/FSL groups under the "professional title" category, as well as by the FW/SCF and GC/SC groups under the "field of specialization" category. The FWS may be replaced if its durability is inadequate to meet the required "degree of repetition of the FWS" [10]. In general, formwork design and formwork planning are conducted by the formwork design engineers (i.e., FD/FSL group) [116]. In addition, formwork and scaffolding companies (i.e., FW/SCF group) should ensure that the FWS has adequate durability to finish the project on time and budget so that the contractors (i.e., GC/SC group) can use the acquired FWS without the need for replacement or repairs. Consequently, "FWS durability" is an important criterion for these groups in the selection of the FWS, which may impact both the cost and the duration of the project.

\subsection{Discussion Based on Hypotheses}

In building construction projects, organisational structures may separate the design teams from the construction teams, and some construction-related decisions may be taken differently [79]. Furthermore, there may be agreements or disagreements among different groups of respondents regarding the relative importance level of some FWS selection criteria $[13,17]$. Hence, differences in perception and perspectives among groups of construction professionals in the decision-making process of FWSs may exist. In this study, the Kruskal-Wallis test and the Mann-Whitney U test were conducted to evaluate Hypothesis 1 and Hypothesis 2, as well as to determine which of the FWS selection criteria resulted in a statistically significant difference between the four response groups in the "professional title" and "field of specialization" categories. The findings revealed that, regarding the relative importance level of the FWS selection criteria, the $\mathrm{CO}, \mathrm{PM} / \mathrm{CM} / \mathrm{SE}$, and PL/PR/TO groups under the "professional title" category had only a few statistical differences among each other. This result is consistent with some of the previous studies [17]. However, the relative importance levels of the FD/FSL group differed significantly from all the other groups (e.g., 23 out of 35 FWS selection criteria between the PL/PR/TO and FD/FSL groups). Similarly, the FW/SCF group under the "field of specialization" category showed significant differences regarding FWS selection criteria with the PMS, ENG/DSG, and GC/SC groups. The differences in the perceptions were mostly observed among structural design-related criteria (e.g., "type of structural slab", "variation in column/wall dimensions and location") and in FWS-FWF characteristics-related criteria (e.g., "FWS flexibility", FWF technical support"). In general, the structural design (i.e., ID1-ID10) and the FWS-FWF characteristics (i.e., ID25-ID35) -related criteria are taken into account during the design phase of the building construction project [10]. On the other hand, the cost- and time-related criteria (e.g., "transportation cost of FWS", "speed of construction") may be considered in the later phases of the building construction project, where other stakeholder groups are involved in the decision-making process of the FWS. As stated previously, the FD/FSL group (or FW/SCF group) is typically in charge of the FWS's planning, designing, and detailing activities. However, other formwork-related activities may be performed by different stakeholders in the FWS supply chain depending on the project delivery system, construction method, type of structure, and capacity of the stakeholder [16]. The involvement of the formwork subcontractor (i.e., the FW/SCF group) in the formwork plan and design processes in collaboration with other groups may minimize design errors and change orders during the construction phase [117]. Therefore, 
to improve the cost and time performance of building construction projects, the perspective and perception of the FD/FSL and FW/SCF groups on the FWS selection criteria should be evaluated in coordination with the other groups.

In regard to Hypothesis 3, the results of the Mann-Whitney U test indicate that some of the "building structural parameters" have a significant effect on the FWS selection criteria, while others do not. The majority of the differences in the relative importance levels for the FWS selection criteria were observed between small and/or medium (i.e., $<20,000 \mathrm{~m}^{2}$ ) and large (i.e., $>20,000 \mathrm{~m}^{2}$ ) building construction projects. In this regard, "speed of construction", "hoisting equipment", and "labour productivity" were affected by the size of the building construction project (i.e., total area of building construction) in addition to the significant statistical differences observed in some structural design and FWS-FWF characteristics-related criteria. Time, or the "speed of construction" in this study's context, is a critical factor in selecting the appropriate FWS [4]. The "speed of construction" and the need for "hoisting equipment" may vary according to the type of the selected FWS [7,21]. As the construction area increases, multiple cranes (e.g., "hoisting equipment") may be needed to perform formwork-related tasks [118]. Hence, the project size may affect FWS selection criteria such as "speed of construction" and "hoisting equipment". Furthermore, "the speed of construction" and "hoisting equipment" can be important factors for formwork-related activities in high-rise building construction [48,119]. Therefore, as shown in this study's results, "hoisting equipment" is also affected by the total building height. In construction projects, "labour productivity" is another criterion that can be affected by the size of the project [108] and the type of the selected FWS [12]. The "labour productivity" of the FWS is also affected by the structural design of the building construction project [120]. As a result, the size of the project and total building height have a significant effect on the "labour productivity" of the FWS, as demonstrated by the results of this study.

\subsection{Discussion Based on Critical FWS Selection Criteria}

The perceptions and perspectives of the three groups in the "professional title" category (CO, PM/CM/SE, and PL/PR/TO groups) and the three groups in the "field of specialization" category (CO, PM/CM/SE, and PL/PR/TO groups) were similar regarding FWS selection criteria in building construction projects. However, the FD/FSL group and FW/SCF group had significant statistical differences in their perceptions and perspectives compared to all the other groups. Despite this result, Spearman's rank correlation test revealed that all four groups in both categories had a strong agreement among the 35 FWS selection criteria. Therefore, based on the results of the mean score analysis (e.g., top five FWS selection criteria) and the Spearman's rank correlation test, the "initial cost of the FWS" (ID 18), "speed of construction" (ID 12), "degree of repetition of the FWS" (ID 6), "type of structural slab" (ID 1), and "type of structural lateral loads-supporting system" (ID 2) can be regarded as the critical FWS selection criteria in building construction projects.

\section{Conclusions}

The purpose of this study was to analyse the FWS selection criteria by comparing the perspectives and perceptions of various construction professionals and stakeholder groups involved in building construction projects in Turkey. For this purpose, first, an intensive literature review was conducted and 35 FWS selection criteria for building construction projects were identified. Then, a questionnaire was developed to measure the relative importance level of the identified FWS selection criteria. Subsequently, the data obtained for the FWS selection criteria were analysed utilizing statistical tests based on the research questions and the demographic background of the respondent groups.

This study has revealed that different groups of construction professionals and companies involved in the decision-making process of FWSs mostly agreed on the relative importance level of FWS selection criteria. However, formwork and scaffolding companies and employees of these companies had significant statistical differences regarding FWS selection criteria, especially among structural design and FWS-FWF characteristics-related 
criteria. The main reason for this result is that these criteria are typically considered during the FWS's planning, designing, and detailing phases, which are traditionally done by the FWF. Since the involvement of the FWF with other stakeholder groups during the design phase can improve the constructability of the building construction project, the perspectives and perceptions of the FD/FSL group or the FW/SCF group (i.e., FWF) should be considered in parallel with other groups of construction professionals and companies. Furthermore, the selected FWS, based on the FWS selection criteria, may have a significant impact on the cost and time performance factors in the later phases of a building construction project. In addition, this study determined that some of the "building structural parameters" had significant effects on the FWS selection criteria in building construction projects. The project size (i.e., total area of building construction) and total building height, in particular, affected the "speed of construction," "hoisting equipment," and "labour productivity" in the building construction projects. Therefore, decision-makers and construction professionals may need to consider these FWS selection criteria and the relevant building structural parameters in the selection process of the FWS to improve the performance factors of the project.

As the formwork-related activities and the selected FWS affect the overall performance of a building construction project, the identification of the critical FWS selection criteria can provide construction professionals with a useful guide in their decision-making process. The results of this study indicate that, although differences between the FD/FSL or FW/SCF and the other groups exist, there was a significant agreement among the overall respondents. Hence, it was determined that the "initial cost of the FWS", "speed of construction", "degree of repetition of the FWS", "type of structural slab", and "type of structural lateral loadssupporting system" are the critical FWS selection criteria in the building construction projects in Turkey. In this regard, since there are many FWS selection criteria, decisionmakers and construction professionals may use these critical criteria in MCDM methods to ease computational efforts and improve the FWS selection process.

There are some limitations to this study. The first limitation is that this study was carried out only in Turkey. However, since Turkish construction professionals and companies operate in domestic as well as in international markets, the results of this study may benefit the global construction community as well. Second, this study focused on FWS selection criteria in building construction projects. For different types of projects, such as industrial or infrastructural projects, other FWS selection criteria can be identified and analysed. In addition, based on the quantitative data presented in this study, factor analysis and structural equation modelling (SEM) may be utilized to group the FWS selection criteria and determine the effects among the FWS selection criteria groupings.

Author Contributions: Conceptualization, T.T.; methodology, T.T.; software, T.T.; validation, T.T., H.T. and G.P.; formal analysis, T.T.; investigation, T.T.; resources, T.T.; data curation, T.T.; writingoriginal draft preparation, T.T.; writing — review and editing, G.P.; visualization, H.T.; supervision, G.P. All authors have read and agreed to the published version of the manuscript.

Funding: This research received no external funding.

Institutional Review Board Statement: Not applicable.

Informed Consent Statement: Not applicable.

Data Availability Statement: The data presented in this study are available on request from the corresponding author.

Conflicts of Interest: The authors declare no conflict of interest.

Ethics Statement: The material presented in this study is the authors' own original work, which has not been previously published elsewhere. The article is not currently being considered for publication elsewhere. The article reflects the authors' own research and analysis in a truthful and complete manner. The article properly credits the meaningful contributions of co-authors and co-researchers. All sources used are properly disclosed. All authors have been personally and actively involved in substantial work leading to the paper and will take public responsibility for its content. 


\section{Appendix A}

Table A1. Demographic information of the respondents.

\begin{tabular}{lccc}
\hline Category & Response & $\begin{array}{c}\text { Frequency of } \\
\text { Respondents (N = 222) }\end{array}$ & Percentage (\%) \\
\hline \multirow{3}{*}{ Educational level } & Bachelor's or equivalent & 136 & 61.3 \\
& Master's or equivalent & 82 & 36.9 \\
Doctoral or equivalent & $20-29$ & 24 & 1.8 \\
& $30-39$ & 74 & 10.8 \\
& $40-49$ & 58 & 33.3 \\
Work experience & $\geq 50$ & 66 & 26.1 \\
& $1-10$ & 59 & 29.7 \\
& $11-20$ & 68 & 26.6 \\
Professional title & $21-30$ & 39 & 30.6 \\
& $\geq 31$ & 56 & 17.6 \\
& Project manager, construction manager, & 54 & 25.2 \\
& and site engineer (PM/CM/SE) & 81 & 36.3 \\
& Planning, procurement, and technical & & 18.9 \\
& office engineer (PL/PR/TO) & 42 & 20.3 \\
\hline & Formwork design/formwork sales & & \\
\hline
\end{tabular}

Table A2. Demographic information of the respondents' company.

\begin{tabular}{lccc}
\hline Category & Response & $\begin{array}{c}\text { Frequency of } \\
\text { Respondents (N = 222) }\end{array}$ & $\begin{array}{c}\text { Percentage } \\
\text { (\%) }\end{array}$ \\
\hline No. of technical and & $1-9$ & 67 & 30.2 \\
administrative & $10-49$ & 54 & 24.3 \\
employees & $50-249$ & 61 & 27.5 \\
& $\geq 250$ & 40 & 18.0 \\
No. of operating years & $1-10$ & 30 & 13.5 \\
in the construction & $11-20$ & 45 & 20.3 \\
sector & $21-30$ & 35 & 15.8 \\
& $\geq 31$ & 112 & 50.5 \\
Field of specialization & Project management service (PMS) & 66 & 29.7 \\
& Fngineering and design (ENG/DSG) & 43 & 19.4 \\
& Formwork and scaffolding (FW/SCF) & 48 & 21.6 \\
Market region & General and/or sub-contractor (GC/SC) & 65 & 29.3 \\
& Only national projects & 69 & 31.1 \\
& Mostly national and partially & 110 & 49.5 \\
& international projects & & 17.1 \\
& Mostly international and partially & 38 & 2.3 \\
\hline
\end{tabular}

Table A3. Building structural parameters of the respondent's current construction project.

\begin{tabular}{lccc}
\hline Category & Response & $\begin{array}{c}\text { Frequency of } \\
\text { Respondents (N = 222) }\end{array}$ & Percentage (\%) \\
\hline Typical building floor area & $<1000 \mathrm{~m}^{2}$ & 68 & 30.6 \\
Total area of building & $>1000 \mathrm{~m}^{2}$ & 154 & 69.4 \\
construction & $<20,000 \mathrm{~m}^{2}$ & 91 & 41.0 \\
Typical building & $>20,000 \mathrm{~m}^{2}$ & 131 & 59.0 \\
floor-to-floor height & $<5$ & 104 & 46.8 \\
Total building height & $>5 \mathrm{~m}$ & 118 & 53.2 \\
& $>36.5 \mathrm{~m}$ & 108 & 48.6 \\
\hline
\end{tabular}


Table A4. Mann-Whitney U test statistics for “building structural parameters" category.

\begin{tabular}{|c|c|c|c|c|}
\hline \multirow{2}{*}{$\begin{array}{l}\text { FWS Selection } \\
\text { Criteria ID No. }\end{array}$} & \multicolumn{4}{|c|}{ Asymp. Sig. (Two-Tailed) of Pairwise Comparison } \\
\hline & $<1000 \mathrm{~m}^{2}$ and $>1000 \mathrm{~m}^{2}$ & $<5 \mathrm{~m}$ and $>5 \mathrm{~m}$ & $<20,000 \mathrm{~m}^{2}$ and $>20,000 \mathrm{~m}^{2}$ & $<36.5 \mathrm{~m}$ and $>36.5 \mathrm{~m}$ \\
\hline 1 & $0.011 *$ & 0.532 & $0.008 *$ & $0.007 *$ \\
\hline 2 & 0.676 & 0.739 & 0.629 & 0.366 \\
\hline 3 & 0.406 & 0.734 & 0.933 & 0.991 \\
\hline 4 & 0.350 & 0.254 & 0.690 & 0.336 \\
\hline 5 & 0.638 & 0.054 & 0.855 & 0.351 \\
\hline 6 & 0.281 & 0.091 & $0.010 *$ & 0.098 \\
\hline 7 & 0.849 & 0.100 & 0.164 & 0.546 \\
\hline 8 & 0.411 & 0.417 & $0.003 *$ & 0.042 * \\
\hline 9 & 0.838 & 0.888 & $0.015^{*}$ & 0.515 \\
\hline 10 & 0.058 & 0.986 & $0.026^{*}$ & 0.523 \\
\hline 11 & 0.450 & 0.588 & 0.067 & 0.558 \\
\hline 12 & 0.154 & 0.388 & $0.033 *$ & 0.029 * \\
\hline 13 & 0.814 & 0.837 & 0.282 & 0.348 \\
\hline 14 & 0.175 & 0.386 & 0.020 * & 0.041 * \\
\hline 15 & 0.866 & 0.919 & 0.463 & 0.339 \\
\hline 16 & 0.594 & 0.961 & 0.390 & 0.693 \\
\hline 17 & 0.662 & 0.864 & 0.280 & 0.783 \\
\hline 18 & 0.349 & 0.010 * & 0.451 & 0.415 \\
\hline 19 & 0.329 & 0.971 & 0.740 & 0.383 \\
\hline 20 & 0.727 & 0.981 & 0.168 & 0.224 \\
\hline 21 & 0.450 & 0.328 & 0.075 & 0.178 \\
\hline 22 & 0.413 & 0.238 & 0.666 & 0.138 \\
\hline 23 & $0.047^{*}$ & 0.167 & 0.004 * & $0.025^{*}$ \\
\hline 24 & 0.931 & 0.658 & 0.407 & 0.415 \\
\hline 25 & 0.359 & 0.452 & 0.649 & 0.323 \\
\hline 26 & 0.154 & $0.045^{*}$ & $<0.001 *$ & $<0.001 *$ \\
\hline 27 & 0.785 & 0.595 & 0.036 * & 0.212 \\
\hline 28 & 0.670 & 0.147 & 0.042 * & 0.263 \\
\hline 29 & 0.630 & 0.322 & $0.002 *$ & 0.300 \\
\hline 30 & 0.745 & 0.940 & 0.287 & 0.018 * \\
\hline 31 & 0.381 & 0.663 & 0.043 & 0.084 \\
\hline 32 & 0.369 & 0.960 & $0.013 *$ & 0.065 \\
\hline 33 & 0.148 & 0.127 & $<0.001 *$ & $<0.001 *$ \\
\hline 34 & 0.280 & 0.136 & $0.012 *$ & $<0.001 *$ \\
\hline 35 & 0.539 & 0.410 & 0.263 & 0.073 \\
\hline
\end{tabular}

* The Mann-Whitney U test is significant at the 0.05 level.

\section{References}

1. Nguyen, L.D.; Nguyen, H.T. Relationship between building floor and construction labor productivity: A case of structural work. Eng. Constr. Archit. Manag. 2013, 20, 563-575. [CrossRef]

2. Tam, C.M.; Tong, T.K.L.; Lau, T.C.T.; Chan, K.K. Selection of vertical formwork system by probabilistic neural networks models. Constr. Manag. Econ. 2005, 23, 245-254. [CrossRef]

3. Hurd, M.K. Formwork for Concrete, 7th ed.; American Concrete Institute: Farmington Hills, MI, USA, 2005.

4. Safa, M.; Reinsma, S.; Haas, C.T.; Goodrum, P.M.; Caldas, C.H. A decision-making method for choosing concrete forming systems. Int. J. Constr. Manag. 2016, 18, 1-12. [CrossRef]

5. Dikmen, S.U.; Sonmez, M. An artificial neural networks model for estimation of formwork labour. J. Civ. Eng. Manag. 2011, 17, 340-347. [CrossRef]

6. Ko, C.H.; Kuo, J.D. Making formwork construction lean. J. Civ. Eng. Manag. 2015, 21, 444-458. [CrossRef]

7. Shin, Y.; Kim, T.; Cho, H.H.; Kang, K.I. A formwork method selection model based on boosted decision trees in tall building construction. Autom. Constr. 2012, 23, 47-54. [CrossRef]

8. John, S.T.; Mohan, A.; Philip, M.S.; Sarkar, P.; Davis, R. An IoT device for striking of vertical concrete formwork. Eng. Constr. Archit. Manag. 2021. [CrossRef]

9. Zayed, T.; Mohamed, E. A case of productivity model for automatic climbing system. Eng. Constr. Archit. Manag. 2014, 21, 33-50. [CrossRef]

10. Terzioglu, T.; Turkoglu, H.; Polat, G. Formwork systems selection criteria for building construction projects: A critical review of the literature. Can. J. Civ. Eng. 2021. [CrossRef] 
11. Elazouni, A.; Ali, A.; Abdel-Razek, R. Estimating the acceptability of new formwork systems using neural networks. J. Constr. Eng. Manag. 2005, 131, 33-41. [CrossRef]

12. Basu, R.; Jha, K.N. An AHP based model for the selection of horizontal formwork systems in Indian residential construction. Int. J. Struct. Civ. Eng. Res. 2016, 5, 80-86. [CrossRef]

13. Proverbs, D.G.; Holt, G.D.; Olomolaiye, P.O. Factors in formwork selection: A comparative investigation. Build. Res. Inf. 1999, 27, 109-119. [CrossRef]

14. Jiang, L.; Leicht, R.M. Automated rule-based constructability checking: Case study of formwork. J. Manag. Eng. 2015, 31, A4014004. [CrossRef]

15. Lee, D.; Lim, H.; Kim, T.; Cho, H.; Kang, K. Advanced planning model of formwork layout for productivity improvement in high-rise building construction. Autom. Constr. 2018, 85, 232-240. [CrossRef]

16. Terzioglu, T.; Polat, G.; Turkoglu, H. Analysis of industrial formwork systems supply chain using value stream mapping. J. Eng. Proj. Prod. Manag. 2022, 12, 47-61. [CrossRef]

17. Rajeshkumar, V.; Anandaraj, S.; Kavinkumar, V.; Elango, K.S. Analysis of factors influencing formwork material selection in construction buildings. Mater. Today Proc. 2021, 37, 880-885. [CrossRef]

18. Jha, J.; Sinha, S.K. Modern Practices in Formwork for Civil Engineering Construction Works; University Science Press: New Delhi, India, 2014.

19. Hansen, S.; Siregar, P.H.R.; Jevica, J. AHP-based decision-making framework for formwork system selection by contractors. J. Constr. Dev. Ctries. 2020, 25, 235-255. [CrossRef]

20. Hanna, A.S. Concrete Formwork Systems; Marcel Dekker: New York, NY, USA, 1999.

21. Elbeltagi, E.; Hosny, O.; Elhakeem, A.; Abd-Elrazek, M.; Abdullah, A. Selection of slab formwork system using fuzzy logic. Constr. Manag. Econ. 2011, 29, 659-670. [CrossRef]

22. Hanna, A.S. An Interactive Knowledge-Based Formwork Selection System for Buildings. Ph.D. Dissertation, Department of Civil Engineering, Pennsylvania State University, State College, PA, USA, 1989.

23. Hanna, A.S.; Sanvido, V.E. Interactive vertical formwork selection system. Concr. Int. 1990, 12, $26-32$.

24. Hanna, A.S.; Willenbrock, J.H.; Sanvido, V.E. Knowledge acquisition and development for formwork selection system. J. Constr. Eng. Manag. 1992, 118, 179-198. [CrossRef]

25. Kamarthi, S.V.; Sanvido, V.E.; Kumara, S.R.T. Neuroform-Neural network system for vertical formwork selection. J. Comp. Civ. Eng. 1992, 6, 178-199. [CrossRef]

26. Hanna, A.S.; Senouci, A.B. NEUROSLAB-Neural network system for horizontal formwork selection. Can. J. Civ. Eng. 1995, 22, 785-792. [CrossRef]

27. Shin, Y. Formwork system selection model for tall building construction using the Adaboost algorithm. J. Korea Inst. Build. Constr. 2011, 11, 523-529. [CrossRef]

28. Kim, T.H. Optimization of the Formwork Selection Process in Tall Buildings. Master's Thesis, Korea University, Seoul, Korea, 2007.

29. Jarkas, A. Buildability factors influencing micro-level formwork labour productivity of slab panels in building floors. Arch. Eng. Des. Manag. 2010, 6, 161-174. [CrossRef]

30. Elbeltagi, E.; Hosny, O.; Elhakeem, A.; Abd-Elrazek, M.; El-Abbasy, M. Fuzzy logic model for selection of vertical formwork systems. J. Constr. Eng. Manag. 2012, 138, 832-840. [CrossRef]

31. Yun, J.; Jeong, K.; Youn, J.; Lee, D. Development of Side Mold Control Equipment for Producing Free-Form Concrete Panels. Buildings 2021, 11, 175. [CrossRef]

32. Darwish, M.; Elsayed, A.Y.; Nassar, K. Design and constructability of a novel funicular arched steel truss falsework. J. Constr. Eng. Manag. 2018, 144, 04018002. [CrossRef]

33. Krawczyńska-Piechna, A. Application of TOPSIS method in formwork selection problem. Appl. Mech. Mater. 2015, 797, 101-107. [CrossRef]

34. Krawczyńska-Piechna, A. An analysis of the decisive criteria in formwork selection problem. Arch. Civ. Eng. 2016, 62, 185-196. [CrossRef]

35. Krawczyńska-Piechna, A. Comprehensive approach to efficient planning of formwork utilization on the construction site. Procedia Eng. 2017, 182, 366-372. [CrossRef]

36. Lee, J.; Cho, J. An inference method of safety accidents of construction workers according to the risk factor reduction of the Bayesian network model in linear scheduling. Int. J. Manag. 2020, 11, 1-12.

37. Hallowell, M.R.; Gambatese, J.A. Activity-based safety risk quantification for concrete formwork construction. J. Constr. Eng. Manag. 2009, 135, 990-998. [CrossRef]

38. Jayasinghe, R.S.; Fernando, N.G. Developing labour productivity norms for aluminium system formwork in Sri Lanka. Built Environ. Proj. Asset Manag. 2017, 7, 199-211. [CrossRef]

39. Jiang, L.; Leicht, R.M.; Kremer, G.E.O. Eliciting constructability knowledge for BIM-enabled automated, rule-based constructability review: A case study of formwork. In Proceedings of the 2014 Construction Research Congress, Atlanta, GA, USA, 19-21 May 2014. [CrossRef]

40. Martinez, E.; Tommelein, I.D.; Alvear, A. Formwork system selection using choosing by advantages. In Proceedings of the Construction Research Congress 2016, San Juan, Puerto Rico, 31 May-2 June 2016; 2016; pp. 1700-1709. [CrossRef] 
41. Radziejowska, A.; Sobotka, A. Comparative analysis of slab formwork of monolithic reinforced concrete buildings. Arch. Civ. Eng. 2020, 66, 127-141. [CrossRef]

42. Loganathan, K.; Viswanathan, K.E. A study report on cost, duration and quality analysis of different formworks in high-rise building. Int. J. Sci. Eng. Res. 2016, 7, 190-195.

43. Rosenbaum, S.; Toledo, M.; González, V. Improving environmental and production performance in construction projects using value-stream mapping: Case study. J. Constr. Eng. Manag. 2014, 140, 1-11. [CrossRef]

44. Vilventhan, A.; Ram, V.; Sugumaran, S. Value stream mapping for identification and assessment of material waste in construction: A case study. Waste Manag. Res. 2019, 37, 815-825. [CrossRef]

45. Spitz, N.; Coniglio, N.; Libessart, L.; El Mansori, M.; Djelal, C. Characterizing tribological behavior of fresh concrete against formwork surfaces. Constr. Build. Mater. 2021, 303, 124233. [CrossRef]

46. Mésároš, P.; Spišáková, M.; Mandičák, T.; Čabala, J.; Oravec, M.M. Adaptive design of formworks for building renovation considering the sustainability of construction in BIM environment-Case study. Sustainability 2021, 13, 799. [CrossRef]

47. Singh, M.M.; Sawhney, A.; Sharma, V. Utilising building component data from BIM for formwork planning. Constr. Econ. Build. 2017, 17, 20-36. [CrossRef]

48. Rajeshkumar, V.; Sreevidya, V. Performance evaluation on selection of formwork systems in high rise buildings using regression analysis and their impacts on project success. Arch. Civ. Eng. 2019, 65, 209-222. [CrossRef]

49. Pawar, A.D.; Rajput, B.L.; Agarwal, A.L. Factors affecting selection of concrete structure formwork. In Proceedings of the 3rd International Conference on Construction, Real Estate, Infrastructure and Project Management, National Institute of Construction Management and Research, Pune, India, 23-25 November 2018; pp. 45-52.

50. Teja, G.S.; Hanagodimath, A.V.; Naik, S.K. Fuzzy logic model for selection of concrete placement methods and formwork systems. In Proceedings of the 3rd International Conference on Construction, Real Estate, Infrastructure and Project Management, National Institute of Construction Management and Research, Pune, India, 23-25 November 2018; pp. 89-98.

51. Lohana, Y. Analysis of productivity criteria for selection of formwork system for construction of high rise building mega projects. In Proceedings of the 3rd International Conference on Construction, Real Estate, Infrastructure and Project Management, National Institute of Construction Management and Research, Pune, India, 23-25 November 2018; pp. 140-154.

52. Ray, P.; Bera, D.K.; Rath, A.K. Comparison between the tunnel form system formwork and the MIVAN formwork system in a multi-unit building project. In Recent Developments in Sustainable Infrastructure; Das, B.B., Barbhuiya, S., Gupta, R., Saha, P., Eds.; Springer: Singapore, 2020; pp. 891-908. [CrossRef]

53. Huszar, Z.; Lubloy, E. Examination of the cost ratio of the formwork. Acta Tech. Jaurinensis 2021, 14, 155-177. [CrossRef]

54. Rajeshkumar, V.; Vinoth, S.; Jayan, S.; Prakash, J.; Kavimani, K.; Praveen, M. Effective selection of formwork using computer application. AIP Conf. Proc. 2021, 2327, 020044. [CrossRef]

55. Yiğit, P. Istanbul housing and land appraisal system reform development process and property values analysis. J. Life Econ. 2020, 7, 59-78. [CrossRef]

56. Türkiye Müteahhitler Birliği. Available online: https://www.tmb.org.tr/files/doc/1623914018902-ydmh-en.pdf (accessed on 23 November 2021).

57. Engineering News-Record. Available online: https://www.enr.com/toplists/2020-Top-250-Global-Contractors-Preview (accessed on 23 November 2021).

58. Jha, K.N. Formwork for Concrete Structures; Tata McGraw-Hill: New Delhi, India, 2012.

59. Al Balkhy, W.; Sweis, R.; Lafhaj, Z. Barriers to adopting lean construction in the construction industry-The case of Jordan. Buildings 2021, 11, 222. [CrossRef]

60. Oke, A.E.; Kineber, A.F.; Albukhari, I.; Othman, I.; Kingsley, C. Assessment of cloud computing success factors for sustainable construction industry: The case of Nigeria. Buildings 2021, 11,36. [CrossRef]

61. Al Balkhy, W.; Sweis, R. Assessing lean construction conformance amongst the second-grade Jordanian construction contractors. Int. J. Constr. Manag. 2019, 1-13. [CrossRef]

62. Samara, A.; Sweis, R.J.; Tarawneh, B.; Albalkhy, W.; Sweis, G.; Alhomsi, S. Sustainability management of international development projects by International Non-Governmental Organizations: The case of INGOs working with refugees in Jordan. Int. J. Constr. Manag. 2020, 1-10. [CrossRef]

63. Preston, C.C.; Colman, A.M. Optimal number of response categories in rating scales: Reliability, validity, discriminating power, and respondent preferences. Acta Psych. 2000, 104, 1-15. [CrossRef]

64. Taherdoost, H. What is the best response scale for survey and questionnaire design; review of different lengths of rating scale/attitude scale/Likert scale. Int. J. Acad. Res. Manag. 2019, 8, 1-10.

65. Simms, L.J.; Zelazny, K.; Williams, T.F.; Bernstein, L. Does the Number of Response Options Matter? Psychometric Perspectives Using Personality Questionnaire Data. Psych. Assess. 2019, 31, 557-566. [CrossRef] [PubMed]

66. Boge, K.; Haddadi, A.; Klakegg, O.J.; Salaj, A.T. Facilitating Building Projects' Short-Term and Long-Term Value Creation. Buildings 2021, 11, 332. [CrossRef]

67. Patel, T.; Bapat, H.; Patel, D.; van der Walt, J.D. Identification of Critical Success Factors (CSFs) of BIM Software Selection: A Combined Approach of FCM and Fuzzy DEMATEL. Buildings 2021, 11, 311. [CrossRef]

68. Türkiye Istatistik Kurumu. Available online: https:// data.tuik.gov.tr/Bulten/Index?p=Paid-Employee-Statistics-July-2021-37504 (accessed on 10 October 2021). 
69. Gamil, Y.; Abdullah, M.A.; Abd-Rahman, I.; Asad, M.M. Internet of things in construction industry revolution 4.0: Recent trends and challenges in the Malaysian context. J. Eng. Des. Tech. 2020, 18, 1091-1102. [CrossRef]

70. Sharma, G. Pros and cons of different sampling techniques. Int. J. Appl. Res. 2017, 3, 749-752.

71. Cochran, W.G. Sampling Techniques; JohnWiley \& Sons: New York, NY, USA, 1977.

72. Albuainain, N.; Sweis, G.; AlBalkhy, W.; Sweis, R.; Lafhaj, Z. Factors Affecting Occupants' Satisfaction in Governmental Buildings: The Case of the Kingdom of Bahrain. Buildings 2021, 11, 231. [CrossRef]

73. Bartlett, J.E.; Kotrlik, J.W.; Higgins, C.C. Organizational research: Determining appropriate sample size in survey research. Inf. Technol. Learn. Perform. J. 2001, 19, 43-50.

74. Hoonakker, P.; Carayon, P.; Loushine, T. Barriers and benefits of quality management in the construction industry: An empirical study. Total Qual. Manag. Bus. Excell. 2010, 21, 953-969. [CrossRef]

75. Ogunmakinde, O.E.; Sher, W.; Maund, K. An assessment of material waste disposal methods in the Nigerian construction industry. Recycling 2019, 4, 13. [CrossRef]

76. Fahmy, A.; Hassan, T.M.; Bassioni, H. Improving RCPSP solutions quality with Stacking Justification-Application with particle swarm optimization. Expert Syst. Appl. 2004, 41, 5870-5881. [CrossRef]

77. Goh, C.S.; Abdul-Rahman, H. The Identification and Management of Major Risks in the Malaysian Construction Industry. J. Constr. Dev. Ctries. 2013, 18, 19-32.

78. Chitkara, K.K. Construction Project Management: Planning, Scheduling and Controlling; McGraw-Hill: New Delhi, India, 2014.

79. Dossick, C.S.; Neff, G. Organizational divisions in BIM-enabled commercial construction. J. Constr. Eng. Manag. 2010, 136, 459-467. [CrossRef]

80. Chen, Y.; Lu, H.; Lu, W.; Zhang, N. Analysis of project delivery systems in Chinese construction industry with data envelopment analysis (DEA). Eng. Constr. Archit. Manag. 2010, 17, 598-614. [CrossRef]

81. Sheskin, D.J. Handbook of Parametric and Nonparametric Statistical Procedures, 5th ed.; Chapman and Hall/CRC: London, UK, 2011.

82. Ahmed, H.; Edwards, D.J.; Lai, J.H.K.; Roberts, C.; Debrah, C.; Owusu-Manu, D.-G.; Thwala, W.D. Post occupancy evaluation of school refurbishment projects: Multiple case study in the UK. Buildings 2021, 11, 169. [CrossRef]

83. Brewerton, P.; Millward, L. Organisational Research Methods; Sage Publications: London, UK, 2001.

84. Sekaran, U. Research Methods for Business: A Skill Building Approach, 4th ed.; John Wiley \& Sons: New York, NY, USA, 2003.

85. Cooper, D.R.; Emory, C.W. Business Research Methods; Irwin: Chicago, IL, USA, 1995.

86. Nunnally, J.; Bernstein, I. Psychometric Theory, 3rd ed.; McGraw-Hill: New York, NY, USA, 1994.

87. Doloi, H.; Sawhney, A.; Iyer, K.C.; Rentala, S. Analysing factors affecting delays in Indian construction projects. Int. J. Proj. Manag. 2012, 30, 479-489. [CrossRef]

88. Sinesilassie, E.G.; Tripathi, K.K.; Tabish, S.Z.S.; Jha, K.N. Modeling success factors for public construction projects with the SEM approach: Engineer's perspective. Eng. Constr. Archit. Manag. 2019, 26, 2410-2431. [CrossRef]

89. Bagozzi, R.P.; Yi, Y.; Phillips, L.W. Assessing Construct Validity in Organizational Research. Adm. Sci. Q. 1991, 36, 421-458. [CrossRef]

90. Kaiser, H.F. An index of factorial simplicity. Psychometrika 1974, 39, 31-36. [CrossRef]

91. Field, A. Discovering Statistics Using IBM SPSS Statistic, 4th ed.; Sage Publications: Thousand Oaks, CA, USA, 2013.

92. Hair, J.F.; Black, W.C.; Babin, B.J.; Anderson, R.E. Multivariate Data Analysis, 7th ed.; Prentice Hall: Hoboken, NJ, USA, 2009.

93. Manzoor, B.; Othman, I.; Gardezi, S.S.S.; Harirchian, E. Strategies for adopting building information modeling (BIM) in sustainable building projects-A case of Malaysia. Buildings 2021, 11, 249. [CrossRef]

94. Montgomery, D.C. Design and Analysis of Experiments; Wiley: New York, NY, USA, 2005.

95. Forza, C. Survey research in operations management: A process-based perspective. Int. J. Oper. Prod. Manag. 2002, 22, 152-194. [CrossRef]

96. Fellows, R.F.; Liu, A.M. Research Methods for Construction, 4th ed.; John Wiley \& Sons: Hoboken, NJ, USA, 2015.

97. Kassem, M.A.; Khoiry, M.A.; Hamzah, N. Risk factors in oil and gas construction projects in developing countries: A case study. Int. J. Energy Sect. Manag. 2019, 13, 846-861. [CrossRef]

98. Raouf, A.M.; Al-Ghamdi, S.G. Managerial Practitioners' Perspectives on Quality Performance of Green-Building Projects. Buildings 2020, 10, 71. [CrossRef]

99. Lam, P.T.; Javed, A.A. Comparative study on the use of output specifications for Australian and UK PPP/PFI projects. J. Perform. Constr. Facil. 2013, 29, 1-11.

100. Siegel, S.; Castellan, N.J. Nonparametric Statistics for the Behavioral Sciences; McGraw-Hill: New York, NY, USA, 1988.

101. Lau, C.H.; Mesthrige, J.W.; Lam, P.T.I.; Javed, A.A. The challenges of adopting new engineering contract: A Hong Kong study. Eng. Constr. Archit. Manag. 2019, 26, 2389-2409. [CrossRef]

102. Hussain, S.; Zhu, F.; Ali, Z.; Aslam, H.D.; Hussain, A. Critical delaying factors: Public sector building projects in Gilgit-Baltistan, Pakistan. Buildings 2018, 8, 6. [CrossRef]

103. Kottegoda, N.T.; Rosso, R. Applied Statistics for Civil and Environmental Engineers; McGraw-Hill: New York, NY, USA, 1997.

104. Bajjou, M.S.; Chafi, A. Empirical study of schedule delay in Moroccan construction projects. Int. J. Constr. Manag. 2018, 20, 783-800. [CrossRef]

105. Zhou, Y.; Yang, Y.; Yang, J.B. Barriers to BIM implementation strategies in China. Eng. Constr. Archit. Manag. 2019, 26, 554-574. [CrossRef] 
106. Olanrewaju, O.I.; Chileshe, N.; Babarinde, S.A.; Sandanayake, M. Investigating the barriers to building information modeling (BIM) implementation within the Nigerian construction industry. Eng. Constr. Archit. Manag. 2020, 27, 2931-2958. [CrossRef]

107. Osei-Kyei, R.; Chan, A.P.C. Empirical comparison of critical success factors for public-private partnerships in developing and developed countries: A case of Ghana and Hong Kong. Eng. Constr. Archit. Manag. 2017, 24, 1222-1245. [CrossRef]

108. Manoharan, K.; Dissanayake, P.; Pathirana, C.; Deegahawature, D.; Silva, R. Assessment of critical factors influencing the performance of labour in Sri Lankan construction industry. Int. J. Constr. Manag. 2020, 1-35. [CrossRef]

109. Fischer, M.; Tatum, C.B. Characteristics of design-relevant constructability knowledge. J. Constr. Eng. Manag. 1997, 123, 253-260. [CrossRef]

110. Shrivastava, A.; Chourasia, D.; Saxena, S. Planning of formwork materials. Mater. Today Proc. 2021, 47, 7060-7063. [CrossRef]

111. Kannan, M.; Santhi, M. Automated constructability rating framework for concrete formwork systems using building information modeling. Asian J. Civ. Eng. 2018, 19, 387-413. [CrossRef]

112. ACI Committee 308. Guide to Curing Concrete; ACI 308R-01; ACI (American Concrete Institute): Farmington Hills, MI, USA, 2001.

113. Malara, J.; Plebankiewicz, E.; Juszczyk, M. Formula for determining the construction workers productivity including environmental factors. Buildings 2019, 9, 240. [CrossRef]

114. Kannan, M.; Santhi, M. Constructability assessment of climbing formwork systems using building information modeling. Procedia Eng. 2013, 64, 1129-1138. [CrossRef]

115. Abou Ibrahim, H.A.; Hamzeh, F.R. Expected lean effects of advanced high-rise formwork systems. In Proceedings of the 23rd Annual Conference of the International Group for Lean Construction, Perth, Australia, 28-31 July 2015; pp. 83-92. [CrossRef]

116. Lee, B.; Choi, H.; Min, B.; Lee, D.-E. Applicability of formwork automation design software for aluminum formwork. Appl. Sci. 2020, 10, 9029. [CrossRef]

117. Ko, C.H.; Kuo, J.D. Making formwork design lean. J. Eng. Proj. Prod. Manag. 2019, 9, 29-47. [CrossRef]

118. Huang, R.Y.; Chen, J.J.; Sun, K.S. Planning gang formwork operations for building construction using simulations. Autom. Constr. 2004, 13, 765-779. [CrossRef]

119. Hyun, H.; Park, M.; Lee, D.; Lee, J. Tower crane location optimization for heavy unit lifting in high-rise modular construction. Buildings 2021, 11, 121. [CrossRef]

120. Jarkas, A.M. Buildability factors affecting formwork labour productivity of building floors. Can. J. Civ. Eng. 2010, 37, 1383-1394. [CrossRef] 